Washington University School of Medicine Digital Commons@Becker

Open Access Publications

2021

\title{
Redox-responsive hyaluronic acid-based nanogels for the topical delivery of the visual chromophore to retinal photoreceptors
}

\author{
Amine M. Laradji \\ Washington University School of Medicine in St. Louis \\ Alexander V. Kolesnikov \\ Washington University School of Medicine in St. Louis \\ Bedia B. Karakoçak \\ Washington University School of Medicine in St. Louis \\ Vladimir J. Kefalov \\ Washington University School of Medicine in St. Louis \\ Nathan Ravi \\ Washington University School of Medicine in St. Louis
}

Follow this and additional works at: https://digitalcommons.wustl.edu/open_access_pubs

Please let us know how this document benefits you.

\section{Recommended Citation}

Laradji, Amine M.; Kolesnikov, Alexander V.; Karakoçak, Bedia B.; Kefalov, Vladimir J.; and Ravi, Nathan, "Redox-responsive hyaluronic acid-based nanogels for the topical delivery of the visual chromophore to retinal photoreceptors." ACS Omega. 6, 9. 6172 - 6184. (2021).

https://digitalcommons.wustl.edu/open_access_pubs/10159

This Open Access Publication is brought to you for free and open access by Digital Commons@Becker. It has been accepted for inclusion in Open Access Publications by an authorized administrator of Digital Commons@Becker. For more information, please contact vanam@wustl.edu. 


\title{
Redox-Responsive Hyaluronic Acid-Based Nanogels for the Topical Delivery of the Visual Chromophore to Retinal Photoreceptors
}

\author{
Amine M. Laradji, Alexander V. Kolesnikov, Bedia B. Karakoçak, Vladimir J. Kefalov, and Nathan Ravi*
}

Cite This: ACS Omega 2021, 6, 6172-6184

Read Online

ABSTRACT: Delivering therapeutics to the posterior segment of the eye is challenging due to various anatomical and physical barriers. While significant improvements have been realized by introducing direct injections to diseased sites, these approaches come with potential side effects that can range from simple inflammation to severe retinal damage. The topical instillation of drugs remains a safer and preferred alternative for patients' compliance. Here, we report the synthesis of penetratin-complexed, redox-responsive hyaluronic acid-based nanogels for the triggered release and delivery of therapeutics to the posterior part of the eye

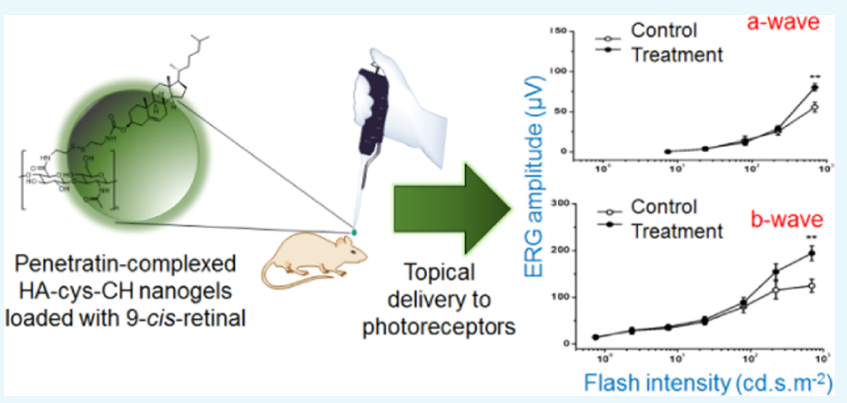
via topical application. The synthesized nanogels were shown to release their load only when exposed to a reducing environment, similar to the cytoplasm. As a model drug, visual chromophore analog, 9-cis-retinal, was loaded into nanogels and efficiently delivered to the mouse retina's photoreceptors when applied topically. Electroretinogram measurements showed a partial recovery of photoreceptor function in all treated eyes versus untreated controls. To the best of our knowledge, this report constitutes the first attempt to use a topically applied triggered-release drug delivery system to target the pigmented layer of the retina, in addition to the first attempt to deliver the visual chromophore topically.

\section{INTRODUCTION}

The eye's posterior side includes the sclera, the retina, choroid, the optic nerve, and the vitreous humor. This part of the eye can be affected by many disorders and diseases that may result in irritation, visual impairment, and even vision loss, such as glaucoma, age-related macular degeneration, and retinopathy. ${ }^{1}$ Relevant to this study, inherited retinal degenerative diseases are a group of disorders that affect the normal function of the retinal photoreceptor cells and are considered a major cause of vision loss. ${ }^{2}$ A significant fraction of these disorders is related to photoreceptors' inability to capture light and generate electric signals to be processed by the brain in a cascade of successive and complex events that are known as phototransduction. ${ }^{3}$ Briefly, light photons are absorbed by visual pigments that consist of the chromophore 11-cis-retinal conjugated to the protein opsin in photoreceptor discs. Consequently, 11-cis-retinal is photoisomerized to all-transretinal, switching the visual pigment to its physiologically active state. Retinal is eventually released from opsin and reduced to the more soluble all-trans-retinol. The retinol is then recycled back to 11-cis-retinal in a process referred to as the visual cycle, which is required for the ability of photoreceptors to detect light continuously. ${ }^{4}$ Paramount to the classic visual cycle is retinal pigmented epithelium (RPE) cells that enzymatically convert all-trans-retinol to 11-cis-retinal and supply photoreceptors with this visual chromophore. ${ }^{5}$ In the RPE cells, chromophore regeneration relies on two important enzymes: lecithin-retinol acyltransferase (LRAT) and $65 \mathrm{kDa}$ retinoid isomerase (RPE65); the lack of either of them has been linked to unavailability of 11-cis-retinal resulting in the impairment of photoreceptor function and retinal degeneration. ${ }^{6-8}$ Inherited retinal degenerations are currently incurable; however, treatments that attempt to control the progress of the disease are available, such as gene augmentation therapy for RPE65 gene mutation-related diseases. $^{9-12}$ A different proposed treatment that has shown promise can be achieved by supplying the retina with exogenous cis-retinoids to bypass the visual cycle and regenerate visual pigments. ${ }^{13-19}$ Nevertheless, the success of any approach is strongly dependent on devising optimized delivery systems that can solely deliver the chromophore to its target site. Furthermore, the optimal method for chromophore delivery must cause minimal to no side effects to prompt patients' compliance.

Van Hooser et al. ${ }^{17}$ studied the effects of intravenous injection of 9-cis-retinal and observed that the disease progression was disrupted, and even some degeneration effects were reversed. More importantly, the effect was shown to last for more than 6 months. However, the disadvantage of this

Received: November 12, 2020

Accepted: February 4, 2021

Published: February 22, 2021 
<smiles>CC(C)CCC[C@H](C)[C@H]1CC[C@H]2[C@@H]3CC=C4C[C@@H](OC(=O)Cl)CC[C@]4(C)C3CC[C@@]21C</smiles><smiles>CC(C)CCC[C@H](C)[C@H]1CC[C@H]2[C@@H]3CC=C4C[C@@H](OC(=O)NCCSSCCN)CC[C@]4(C)[C@H]3CC[C@@]21C</smiles>

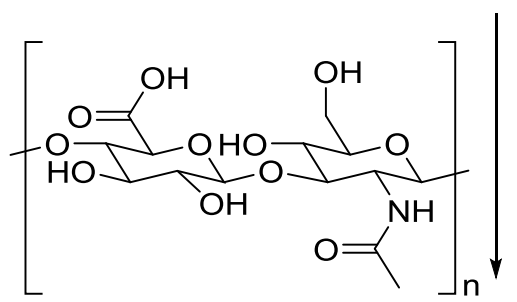

EDC, NHS

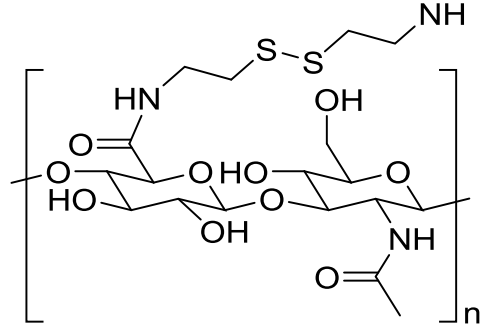

Figure 1. Synthesis steps for the preparation of HA-cys-CH conjugate.

method is the possibility of rapid clearance of the chromophore by the kidneys, which requires the injection of large doses, raising the prospect of infection and toxicity. The same concern is expressed when cis-retinoids are delivered via intravitreal injection. The needed frequent injections to maintain the level of the retinoid, in this case, can also lead to complicated side effects. ${ }^{20-22}$

Because the treatment of inherited retinal degenerations caused by retinal deficiency requires an ongoing long-term administration of the visual chromophore, a topical application would be the most preferred method for safety reasons and patients' compliance. Nevertheless, the use of drug instillation constitutes a significant challenge as drug delivery is hindered by physiological and anatomical barriers inside the eye. ${ }^{23,24}$

Drug administration via the concept of targeted delivery is widely acknowledged because of its ability to mediate equilibrium between the therapeutic effects and side effects of a drug. For that purpose, polymer-based nanogels have been used for decades for various applications. One particular material is redox-responsive nanogel, where the drug is released in a reducing environment. ${ }^{25}$ 

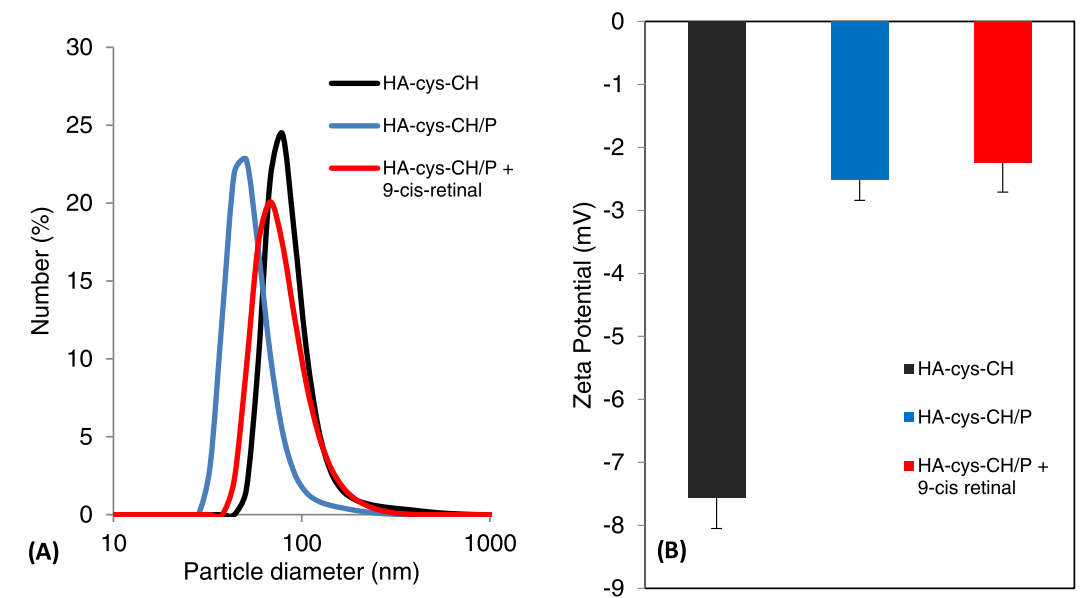

Figure 2. Physical characteristics of nanogel's (A) size and (B) $\zeta$ potential at different stages of synthesis and drug loading steps.

Here, we report our first attempt to deliver the visual chromophore chemical analog, 9-cis-retinal, to photoreceptor cells of the retina via its topical application using penetratincomplexed, redox-responsive nanogels. The nanogels were formed immediately upon dispersion of hyaluronic acidcystamine-cholesterol ( $\mathrm{HA}-\mathrm{cys}-\mathrm{CH})$ conjugate in deionized (DI) water. HA is a natural ligand for the cluster of

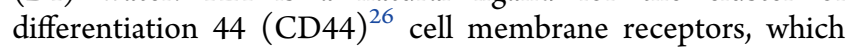
were shown to be expressed on the surface of RPE and Muller cells of the retina in vertebrates. ${ }^{27,28}$ To track their destination, nanogels were covalently tagged with fluorescein. Finally, nanogels were loaded with 9-cis-retinal, and their delivery to mouse photoreceptors was studied both in retinal explants (ex vivo) and in vivo.

\section{RESULTS AND DISCUSSION}

2.1. Synthesis of Hyaluronic Acid-Cystamine-Cholesterol Conjugate (HA-Cys-CH). Redox-responsive nanogels were prepared via a two-step synthesis. In the first step, cholesteryl chloroformate, via its acyl chloride, was reacted with the primary amine group of cystamine free base to yield amine-terminated cholesterol. The second step consisted of conjugating the amine-terminated cholesterol, via its primary amine groups, to the carboxylic groups of hyaluronic acid using an $N$-(3-dimethylaminopropyl)- $N^{\prime}$-ethylcarbodiimide hydrochloride (EDC) coupling protocol (Figure 1).

The ${ }^{1} \mathrm{H}$ NMR spectroscopy confirmed the successful conjugation of cystamine-modified cholesterol to hyaluronic acid (Figure S1). The NMR spectrum contained the characteristic peaks of cholesterol between 0.5 and $1.8 \mathrm{ppm}$. Furthermore, the peak at $5.3 \mathrm{ppm}$ was ascribed to the alkene group of cholesterol. In the same spectrum, HA characteristic peaks were shown between 3.5 and $4.5 \mathrm{ppm}$. Using the same NMR spectrum, the number of conjugated cholesterol to HA was estimated to be eight cholesterol moieties per chain of HA. Modifying HA with the hydrophobic cholesterol moiety leads to modifying its physicochemical properties, including its solubility. This modification can, therefore, be exploited by loading an appropriately hydrophobic drug for pharmaceutical applications. ${ }^{29-33}$ Stimuli-responsive nanocarriers are widely recognized due to their advantages over traditional nanocarriers in drug delivery. ${ }^{34}$ These responsive nanocarriers can undergo physical or chemical changes to respond to externally applied stimuli, making them good candidates to address the drawbacks of drugs' nonselectivity. Our nanogels are endowed with disulfide bonds that are susceptible to reduction. This property makes redox-sensitive nanogels particularly attractive due to the existence of substantial redox potential difference between the extracellular environment and the more reducing environment of the cytoplasm and cell nucleus. ${ }^{35}$ Furthermore, the synthesized nanogels are made of hyaluronic acid. Using $\mathrm{HA}$ is intended to enhance biocompatibility, cellular uptake, drug solubility, and specific retina targeting via CD44 cell receptors. ${ }^{36}$ The prepared $\mathrm{HA}-\mathrm{cys}-\mathrm{CH}$ conjugate can form nanogels immediately upon dispersion in DI water. The size and $\zeta$ potential of the formed nanogels at various steps were investigated by dynamic light scattering (DLS) (Figure 2) and transmission electron microscopy (Figure S2). The formed nanogels exhibited a small particle size with a single peak at around $80 \mathrm{~nm}$, which indicates an absence of aggregation. Upon cross-linking of the nanogels, however, the size of the nanogels decreased as the nanogel's structure became compact (Figure S3), but finally increased after drug loading, reaching a final size of $68 \mathrm{~nm}$. For an efficient delivery to the retina, nanogel's size has to be large enough to avoid clearance through blood vessels and small enough to seep through various eye barriers. ${ }^{37}$ In addition to their small size, the $\zeta$ potential changed from -7.56 to $-2.24 \mathrm{mV}$ after penetratin complexation due to its cationic character. It can be concluded that the nanogels'charge was not affected by drug loading. Nanoparticles' behavior, including their stability and toxicity in living systems, is tightly related to their surface properties, particularly to the $\zeta$ potential, for which positive values predict higher interactions with living systems, and consequently, potentially higher toxicity. ${ }^{38}$ In our case, $\zeta$ potential measurements were done at $\mathrm{pH} 7.4$, which mimics the cytoplasm environment $(\mathrm{pH} \sim 7.2)$, and the synthesized nanogels were negatively charged because of the ionized carboxylic groups of $\mathrm{HA}$ at this $\mathrm{pH}$.

2.2. Release Profile of Loaded Nanogels. Initially, nanogels were loaded with fluorescein as a model hydrophobic molecule, followed by cross-linking using a thiol-disulfide exchange reaction. ${ }^{39-41}$ The working mechanism of nanogels' self-assembly, covalent cross-linking, and drug release is illustrated in Scheme S1. Adding a catalytic amount of 1,4dithiothreitol (DTT) to the self-assembled nanogels results in HA chains cross-linking through the thiol-disulfide exchange reaction. Eventually, when a high concentration of DTT is added, the covalent cross-links between HA chains break, resulting in load release. The fluorescein release profile was 

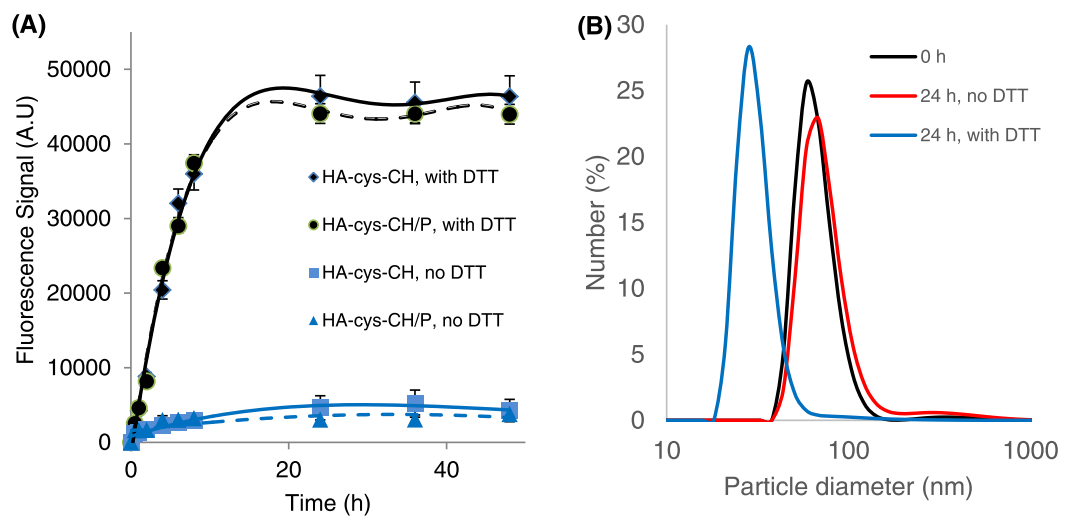

Figure 3. (A) Triggered-release profile of fluorescein from the redox-sensitive $\mathrm{HA}-\mathrm{cys}-\mathrm{CH}$ and $\mathrm{HA}-\mathrm{cys}-\mathrm{CH} / \mathrm{P}$ nanogels showing that the presence of $10 \mathrm{mM}$ DTT causes the disintegration of covalent cross-links of nanogels to release their load. (B) Change of nanogel's size by DLS in response to $10 \mathrm{mM}$ DTT.

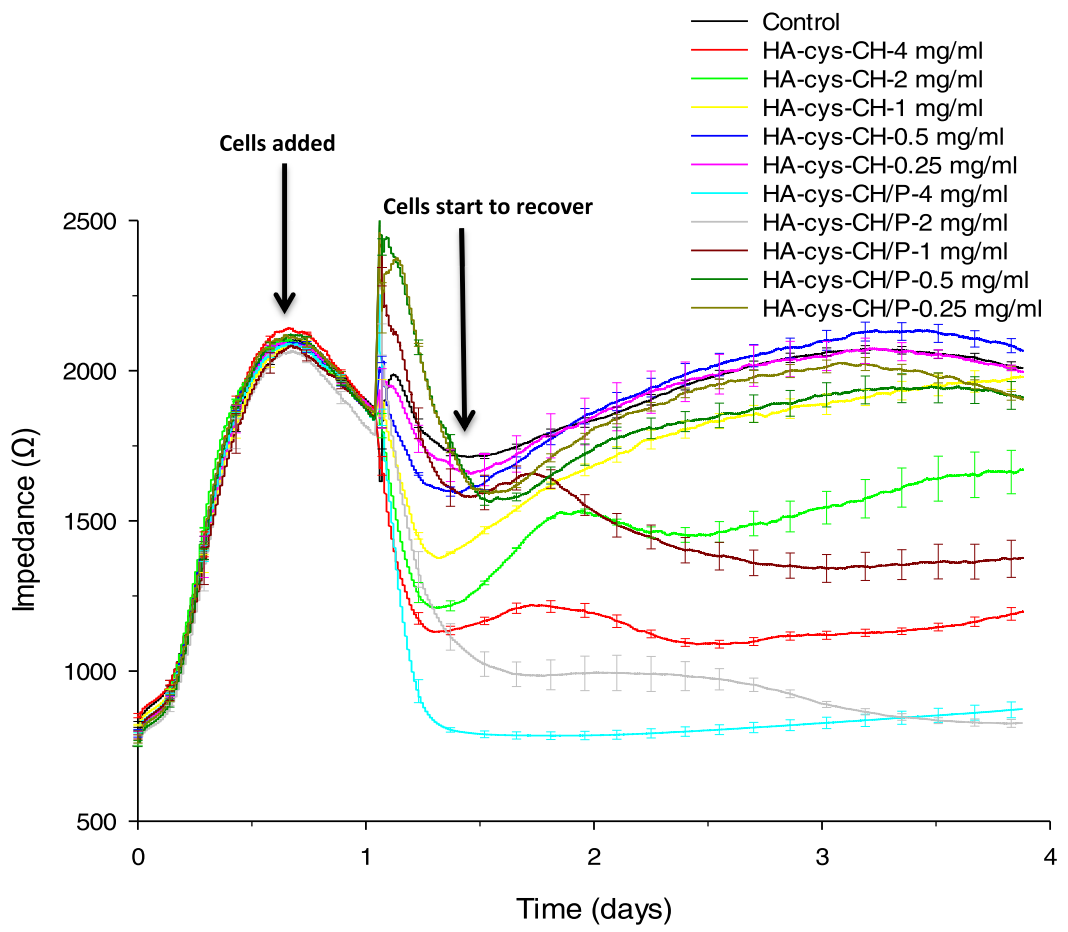

Figure 4. Real-time monitoring of cell attachment behavior using ECIS in response to $\mathrm{HA}-\mathrm{cys}-\mathrm{CH}$ and $\mathrm{HA}-\mathrm{cys}-\mathrm{CH} / \mathrm{P}$ exposure. The HA-based nanogels were biocompatible with ARPE-19 cells at the exposure concentrations of $1 \mathrm{mg} / \mathrm{mL}$ and below.

studied at $\mathrm{pH} 7.4$ and $37^{\circ} \mathrm{C}$ in the presence or absence of 10 mM DTT. As shown in Figure 3A, a negligible fluorescein release from cross-linked nanogels was detected in the absence of a reducing environment. When nanogels were dispersed in $10 \mathrm{mM}$ DTT, however, fluorescein release was immediate and quantitative, indicating that drug release is sensitive to the intracellular reductive environment. To further illustrate the sensitivity of the cross-linked nanogels to a redox environment, the change of their size was observed in the presence and absence of $10 \mathrm{mM}$ DTT. Twenty-four hours after incubation, the size of the cross-linked nanogels was observed to decrease to less than $30 \mathrm{~nm}$, mirroring the disintegration of nanogels' structure in a reducing environment. In the absence of DTT, however, the change in particle size was insignificant (Figure $3 \mathrm{~B})$. It is to be noted that the redox sensitivity of the nanogels was not affected by their complexation by the cell-penetrating peptide penetratin. The reduction-triggered release of these nanogels is an important property that will translate into efficient drug delivery inside the target cells. It is worth noting that the release time of fluorescein from the cross-linked nanogels reflects both the responsiveness time of the nanogels and the diffusion time of fluorescein through the dialysis membrane.

2.3. Biocompatibility Assessment of the Nanogels by Electrical Cell-Substrate Impedance Sensing (ECIS) Analysis. The attachment of ARPE-19 cells in the presence of $\mathrm{HA}-\mathrm{cys}-\mathrm{CH}$ was monitored through electrical cellsubstrate impedance sensing (ECIS) analysis in real time. As seen in Figure 4, the cell detachment amount, which corresponds to higher cytotoxicity, increased as the nanogel exposure concentration increased. According to the results obtained above $0.5 \mathrm{mg} / \mathrm{mL}$, cell growth was significantly hindered for HA-cys-CH and HA-cys-CH/P. The ARPE19 cells started to detach from the plate almost immediately 

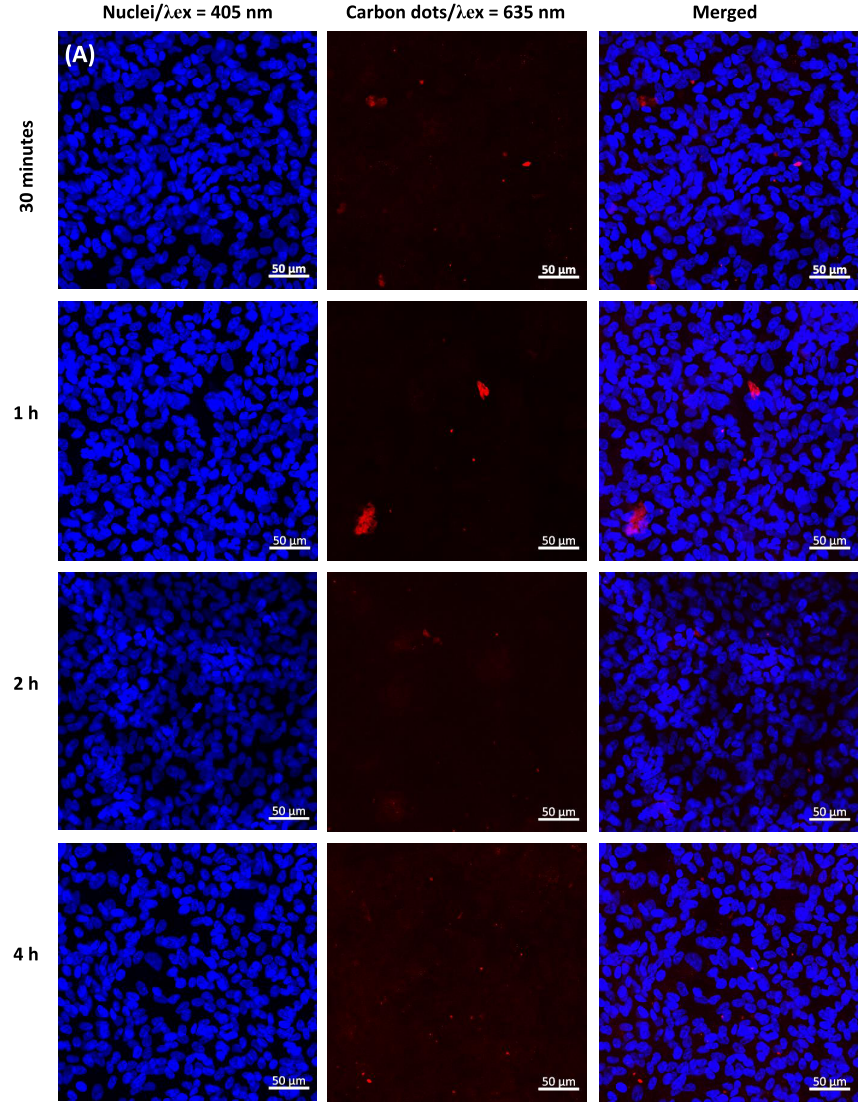
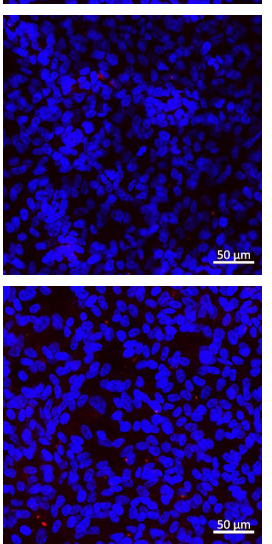
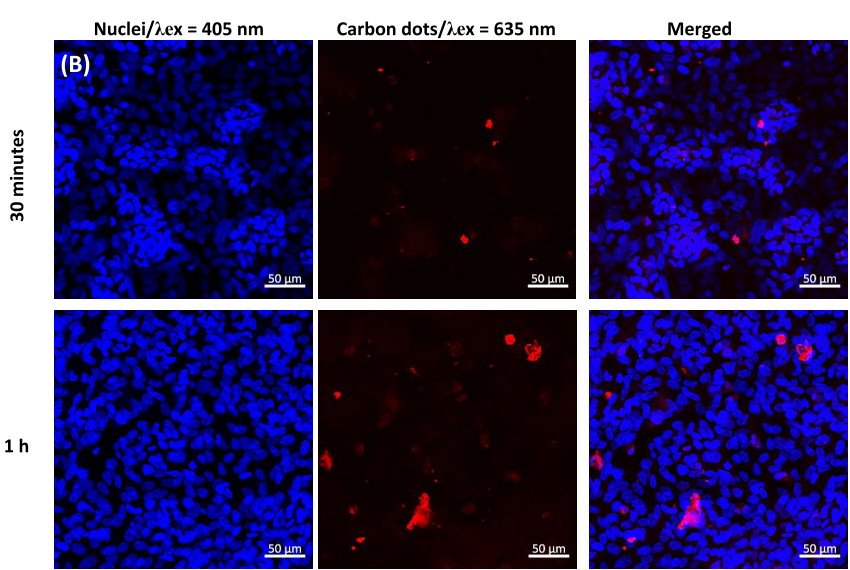

$2 \mathrm{~h}$
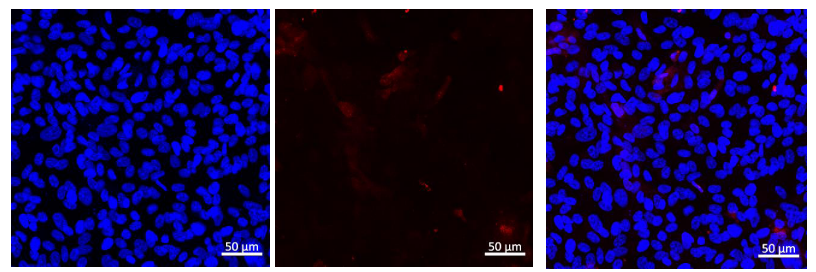

$4 \mathrm{~h}$
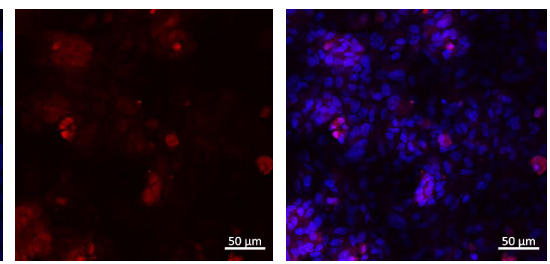

Figure 5. Confocal microscopy images of ARPE-19 cells exposed to $2 \mathrm{mg} / \mathrm{mL}$ carbon dot-conjugated nanogels (A) without and (B) with penetratin at $30 \mathrm{~min}, 1 \mathrm{~h}, 2 \mathrm{~h}$, and $4 \mathrm{~h}$. Penetratin coating significantly increased the intracellular concentration of the nanogels.

following the exposure to a concentration of $4 \mathrm{mg} / \mathrm{mL}$ of nanogels. Overall, all three concentration levels above $0.5 \mathrm{mg} /$ $\mathrm{mL} ; 1,2$, and $4 \mathrm{mg} / \mathrm{mL}$ caused a significant decrease in the cell impedance recordings in the first $\sim 6 \mathrm{~h}$ following the exposure to nanogels. After the sixth hour, the cells started to recover; however, only the cells exposed to $1 \mathrm{mg} / \mathrm{mL}$ of $\mathrm{HA}-\mathrm{cys}-\mathrm{CH}$ and $0.5 \mathrm{mg} / \mathrm{mL}$ of $\mathrm{HA}-\mathrm{cys}-\mathrm{CH} / \mathrm{P}$ could recover completely (reached the same impedance level as control cells). Previously, we showed that the HA coating on nanoparticles not only assists nanoparticle's internalization but also protects the cells from reactive oxygen species (ROS) damage. ${ }^{42}$ The cytotoxicity observed at higher concentrations is probably due to the high accumulation of cholesterol and formation of needle-shaped crystals, ${ }^{43}$ as a result of the disulfide bond breaking between hyaluronic acid and cholesterol in the reducing environment inside the cells. Furthermore, higher free cholesterol levels above the physiological concentration are likely to halt the formation of membrane domains. ${ }^{44}$ On the other hand, penetratin complexation seems to increase the toxicity of the nanogels. While previous studies have already shown that penetratin does not affect cell viability, ${ }^{45,46}$ including for ocular applications, ${ }^{47}$ in our case, the increase in toxicity is likely due to increased cellular uptake of HAcys- $\mathrm{CH} / \mathrm{P}$ versus $\mathrm{HA}-$ cys $-\mathrm{CH}$.

2.4. Cellular Uptake of Nanogels. Next, we studied the time-dependent cellular internalization of nanogels that were either modified or not modified with penetratin. This cellpenetrating peptide has been previously used to enhance ocular permeability and drug targeting to the retina. ${ }^{47,48}$ Penetratin-complexed HA was shown to have a good distribution in the posterior part of the eye even when applied topically. In this study, to assess the extent of the cellular uptake of the nanogels, and for the in vitro imaging, ARPE-19 cells were used. Carbon dots (CD) with a diameter of less than $5 \mathrm{~nm}$ were here used for labeling purposes as we previously reported. ${ }^{49}$ As seen in Figure 5, cellular uptake was observed to increase with a longer incubation time for nanogels both with and without penetratin complexation. Within the studied time, the maximum signal was reached after 4-h incubation. Nanogels interact with cells according to their surface functionalization. ARPE-19 cells have a high density of CD44 receptors; we previously showed that coating nanoparticles of higher than $50 \mathrm{~nm}$ diameter with hyaluronic acid leads to their efficient uptake by ARPE-19 cells via CD44 receptor-mediated endocytosis. ${ }^{42}$ When nanogels were complexed with penetratin, however, the fluorescence intensity increased, indicating their higher cellular internalization as compared to that for non-penetratin-complexed nanogels.

2.5. Administration of 9-cis-Retinal-Loaded Nanogels to Photoreceptors in Isolated Retinas of Rpe65 ${ }^{-1-}$ Mice. An efficient enzymatic reisomerization of the chromophore in RPE cells as a part of the canonical visual cycle and its subsequent supply to retinal photoreceptors are essential for absorbing the light and transduce the visual signal constantly. To establish the principle applicability of our designed nanogels for the delivery of cis-retinoids to photoreceptors in mice, we took advantage of the RPE65-deficient mouse line, a widely accepted model of human Leber congenital amaurosis type 2 (LCA2) retinal disease. While most cone photoreceptors die within the first 3 weeks in $R p e 65^{-/-}$animals, due 
A

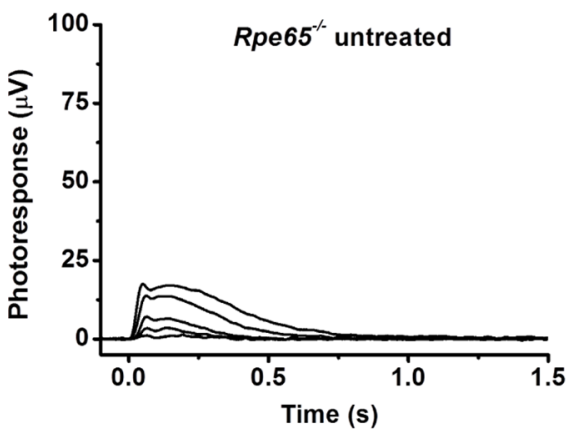

C

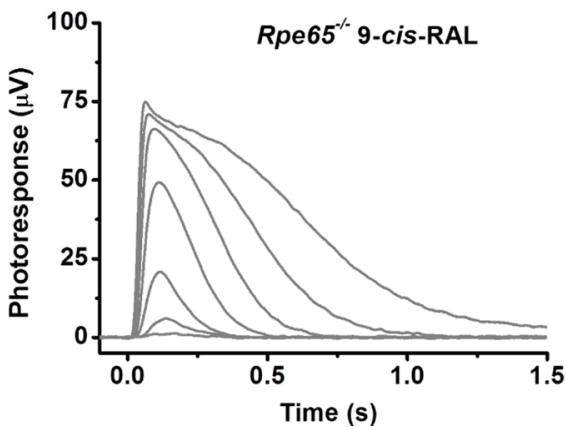

B
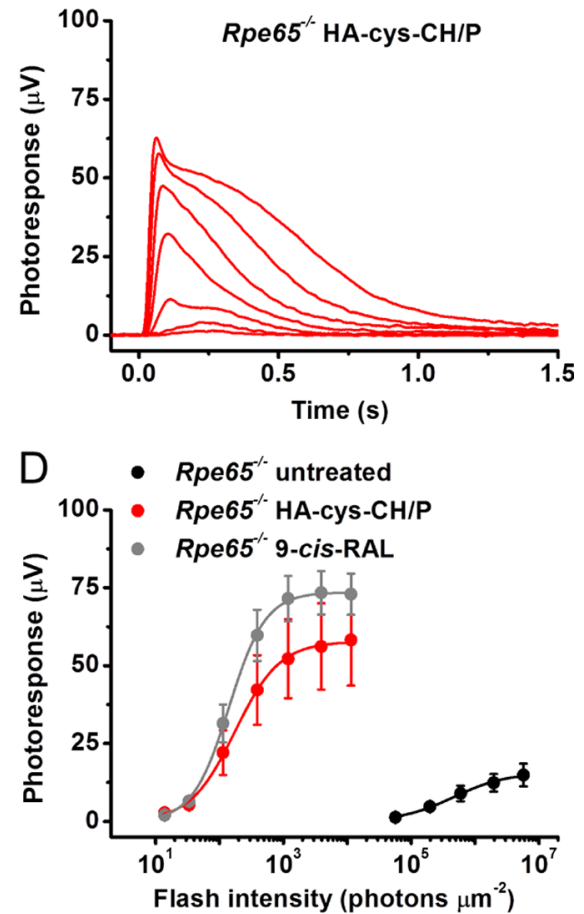

Figure 6. Acute treatment with nanogels loaded with 9-cis-retinal largely restores the amplitude and sensitivity of chromophore-deficient mouse photoreceptors ex vivo. (A) Representative family of transretinal rod ERG responses from Rpe65 ${ }^{-/-}$mouse retinas. Test flashes of $505 \mathrm{~nm}$ light with intensities of $5.7 \times 10^{4}, 2.0 \times 10^{5}, 6.0 \times 10^{5}, 2.0 \times 10^{6}$, and $5.7 \times 10^{6}$ photons $/ \mu \mathrm{m}^{2}$ were delivered at time 0 . (B) Representative family of transretinal rod ERG responses from Rpe65 ${ }^{-1-}$ mouse retinas treated with HA-cys-CH nanogels loaded with 9-cis-retinal in the presence of penetratin. Test flashes of $505 \mathrm{~nm}$ light with intensities of $14,33,114,392,1.2 \times 10^{3}, 3.9 \times 10^{3}$, and $1.1 \times 10^{4}$ photons $/ \mu \mathrm{m}^{2}$ were delivered at time 0. (C) Representative family of transretinal rod ERG responses from Rpe $65^{-/-}$mouse retinas treated with 9-cis-retinal only. Test flashes of $505 \mathrm{~nm}$ light with the same intensities as in (B) were delivered at time 0. (D) Averaged rod intensity-response functions (mean \pm scanning electron microscopy $(\mathrm{SEM}))$ for untreated Rpe65 $5^{-/-}$isolated retinas $(n=4)$ and $R p e 65^{-1-}$ retinas treated either with HA-cys-CH nanogels loaded with 9cis-retinal in the presence of penetratin $(n=3)$ or free 9-cis-retinal in the media $(n=7)$. Error bars for some points are smaller than the symbol size. Hyperbolic Naka-Rushton fits yielded half-saturating intensities $\left(I_{1 / 2}\right)$ of $4.7 \times 10^{5}, 175$, and 142 photons $/ \mu \mathrm{m}^{2}$.

to a greatly impaired RPE visual cycle resulting in misfolding and mislocalization of cone opsins, ${ }^{50-52}$ the rods in this strain do not degenerate appreciably until about 7 weeks of age. ${ }^{53}$ Importantly for our study, rods in these mice are mostly devoid of the chromophore and, as a result, highly desensitized. However, their function can largely be restored with the application of exogenous retinoids. ${ }^{16,17,54}$

Similarly to fluorescein, a commercially available analog of the visual chromophore, 9-cis-retinal, was loaded into HAcys- $\mathrm{CH}$ nanogels followed by cross-linking. The loading content was estimated by UV-vis spectroscopy (after determining $\lambda_{\max }=378 \mathrm{~nm}$ of 9-cis-retinal in dimethyl sulfoxide (DMSO)). Using a standard curve of various concentrations of this retinoid in DMSO, the loading content was quantified to be $18.7 \%$. The efficacy of nanogel-driven administration of 9-cis-retinal was next examined in isolated retinas of chromophore-deficient mouse line lacking RPE65 protein $\left(\right.$ Rpe $\left.65^{-/}\right)$, using a method similar to the one for the acute delivery of 9-cis-retinal established by us previously. ${ }^{54}$ After reaching and penetrating photoreceptor outer segments (POS), the cross-linked nanogels are expected to release their 9-cis-retinal upon reduction of the disulfide bond by intracellular glutathione, and the retinoid would then recombine with free opsin in the discs to regenerate the visual pigment.

Transretinal (ex vivo) electroretinogram (ERG) recordings were performed in the presence of postsynaptic inhibitors blocking contributions of higher-order response components (such as ERG b-wave driven by ON bipolar cells), ${ }^{55}$ thus allowing us to isolate the photoreceptor-driven component of the ERG photoresponse (Figure 6). Because mouse M-cones in the $R p e 65^{-/-}$line produce negligible light responses to green light after 3 weeks of age due to their rapid degeneration, ${ }^{54}$ we assumed that essentially all responses in 6-week-old RPE65-deficient animals we used in this study were generated by rods. As expected, chromophore-deficient rods in control untreated Rpe $65^{-/-}$mice exhibited very small responses to test flashes of green light (Figure 6A) and were desensitized by $>2000$-fold as compared with those from typical wild-type animals (Figure 6D, black symbols), as reported earlier. ${ }^{54,56}$ The administration of nanogels loaded with 9-cis-retinal in the presence of penetratin effectively restored the rod response amplitude (Figure 6B) and sensitivity in this mouse model (Figure $6 \mathrm{D}$, red symbols). The extent of rod resensitization was comparable to that observed upon treatment of Rpe65 $5^{-/-}$retinas with pure 9-cisretinal dissolved in the incubation media (Figure 6C,D, gray symbols), and it remained only $\sim 4$ times lower than the sensitivity of wild-type mouse rods. ${ }^{54}$ The bulk of the latter difference is likely due to the 3 -fold lower quantum efficiency of vertebrate isorhodopsin (a pigment formed with 9-cisretinal) compared to rhodopsin, in which opsin is bound to native 11-cis-retinal. ${ }^{57}$ These results demonstrate the applicability of $\mathrm{HA}-\mathrm{cys}-\mathrm{CH}$ nanogels for chromophore delivery to 
photoreceptor cells in retinal explants and its ability to drive rod visual pigment regeneration.

2.6. Topical Application of Fluorescein-Conjugated Nanogels to Mouse Eyes. The ultimate goal of this study was to develop a reliable noninvasive method for nanoparticlemediated delivery of cis-retinoids and, eventually, other ocular drugs to retinal photoreceptors in vivo via topical administration. As a test approach, some of our $\mathrm{HA}-\mathrm{cys}-\mathrm{CH}$ nanogels were covalently conjugated with fluorescein to trace, by immunohistochemistry, the distribution of the label in the retina and RPE after their topical application to mouse eyes. As expected, no fluorescence was detected in the control sample of phosphate-buffered saline (PBS)-treated or fluoresceintreated eyes (Figure 7A,B). Due to its hydrophobicity, free

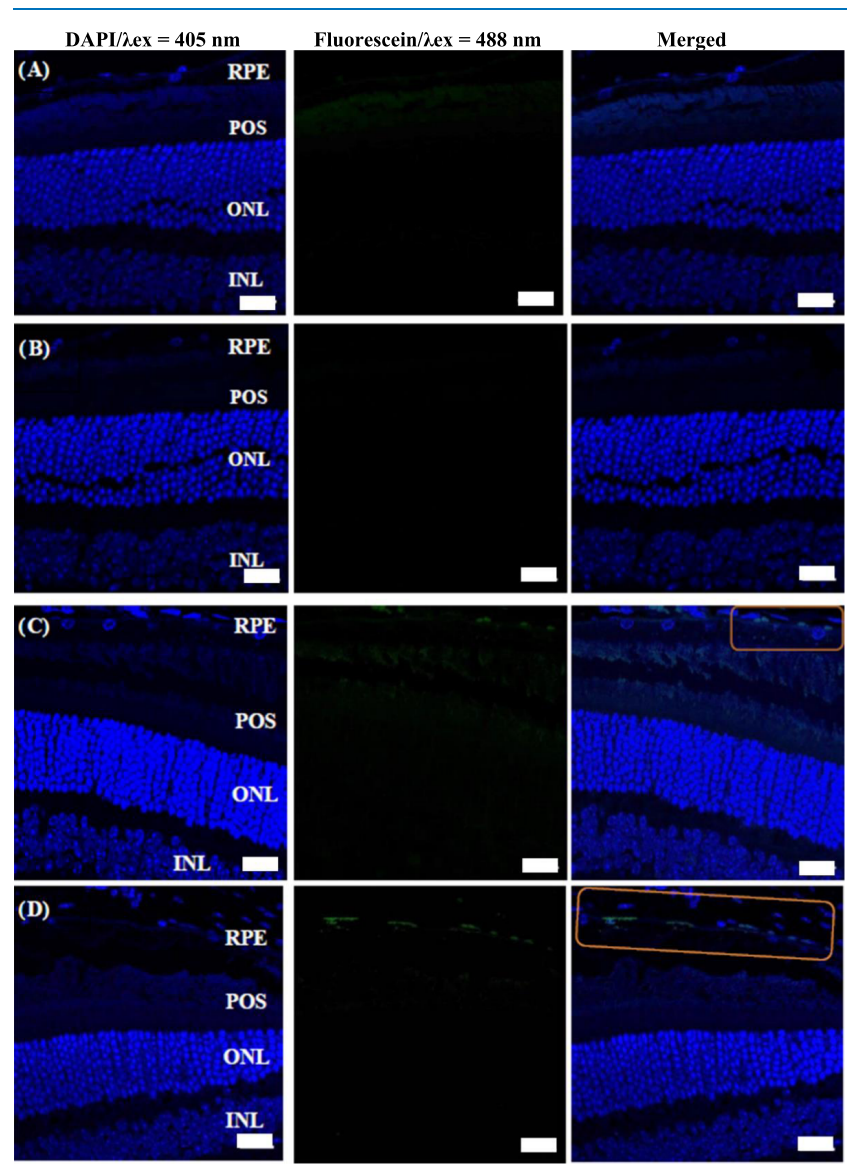

Figure 7. Confocal microscopy images of retinal cross sections after topical application of (A) PBS buffer, (B) fluorescein-only, (C) fluorescein-labeled nanogels without penetratin, and (D) fluoresceinlabeled-nanogels with penetratin complexation. The presence of the nanogels can be seen in the marked section. RPE, retinal pigmented epithelium; POS, photoreceptor outer segments; ONL, outer nuclear layer; and INL, inner nuclear layer. Scale bars are $20 \mu \mathrm{m}$. The sections are stained only for $4^{\prime}, 6$-diamidino-2-phenylindole (DAPI), the nucleus staining (blue). Green particles are the fluorescein-labeled nanogels.

fluorescein could not cross the various ocular barriers. In contrast, hyaluronic acid-based nanogels were able to reach the RPE cells as evidenced by detection of the fluorescence signal at the RPE layer, but not in any of the retinal layers of eyes treated with fluorescein $\mathrm{HA}-\mathrm{cys}-\mathrm{CH}$ nanogels (Figure 7C). A robust fluorescence signal from nanogels was, however, more visible in the RPE layer treated with penetratin-complexed fluorescein $\mathrm{HA}-\mathrm{cys}-\mathrm{CH}$ nanogels (Figure 7D), which further highlights the role of the cell-penetrating peptide to enhance cellular uptake of the nanogels. The RPE cell layer is a single layer that is located next to the photoreceptor cells. Because its dysfunction may lead to visual impairment, RPE cells are often the target of treating ocular diseases. ${ }^{58}$ Therefore, the distribution of nanogels in RPE cells opens a potential for new, more convenient approaches to treat ocular diseases by simple topical application.

It is noteworthy to mention that there are two possible ways the drug delivery systems can reach the retina upon instillation: either through the cornea vitreous or the conjunctival-scleral routes. The latter route, however, is likely the dominant path, as reported previously. ${ }^{59}$ Furthermore, the physical characteristics of our drug delivery system, including its relatively small size, negative surface charge, and hydrophilicity, likely facilitated the nanogels to cross through the porous, hydrophilic, negatively charged scleral constituents. ${ }^{60}$ It is also worth mentioning that the increased fluorescence signal in the RPE layer is consistent with the higher expression of CD44 cell receptors in these cells compared to others, for which hyaluronic acid is a ligand. ${ }^{27}$

2.7. Topical Application of 9-cis-Retinal-Loaded Nanogels to Mouse Eyes. Finally, we examined the possibility of delivering the visual chromophore to photoreceptors in vivo with the topical application of penetratincomplexed $\mathrm{HA}-\mathrm{cys}-\mathrm{CH}$ nanogels loaded with 9-cis-retinal within a $2 \mathrm{~h}$ therapeutic window. During this period, the application of the compound mixture to the right eye of the live anesthetized mouse was repeated three times (see Materials and Methods), and the left (control) eye received the equivalent volume of PBS solution. This procedure improved the experimental outcome compared to a single drug application, as was established in preliminary tests. The experiment was followed by standard ERG recordings from these animals (Figure 8).

First, we confirmed that photoreceptors (likely, predominantly rods) in 6-week-old Rpe65 $5^{-/-}$mice indeed responded to bright light in vivo, even in the absence of the chromophore. They generated typical ERG responses with the initial negative component (rod-driven ERG a-wave) followed by larger positive ERG b-wave driven by rod ON bipolar cells. As in the case of transretinal recordings (Figure 6), the magnitudes of both a- and b-wave ERG components in these animals were several-fold lower than those in wild-type mice with a normally operating RPE visual cycle, and their photosensitivity was reduced dramatically as well. Notably, we found that the topical treatment with 9-cis-retinal-loaded nanogels in the presence of penetratin increased maximal response amplitudes of both ERG a- and b-waves in respective eyes by $40-50 \%$. However, the effect was statistically significant $(P<0.01)$ only at the brightest light intensity $\left(700 \mathrm{~cd} \mathrm{~s} / \mathrm{m}^{2}\right)$ produced by our ERG apparatus (Figure $8 \mathrm{~A}, \mathrm{~B}$ ). The rod sensitivity of drugtreated mice remained unchanged. In the absence of penetratin, topically applied 9-cis-retinal-loaded nanogels were ineffective for restoration of rod responses in live $\mathrm{Rpe}^{-/-}$mice (Figure 8C,D), as was 9-cis-retinal alone (Figure $8 \mathrm{E}, \mathrm{F}$ ). These results clearly highlight the role of penetratin in our drug delivery system in improving drug bioavailability through the enhancement of nanogel transport via the various ocular barriers.

Despite the partial recovery of photoreceptor function in the presence of 9-cis-retinal chromophore delivered by our 
A

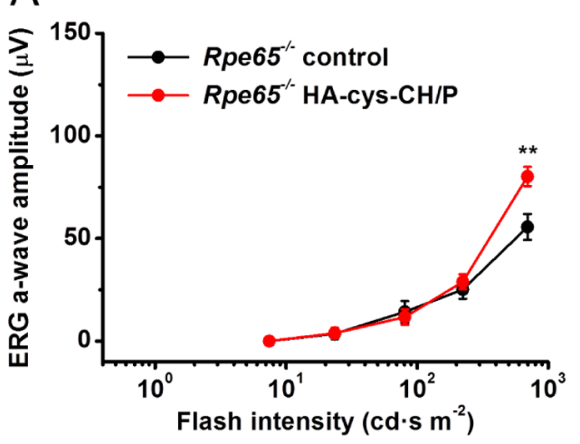

C
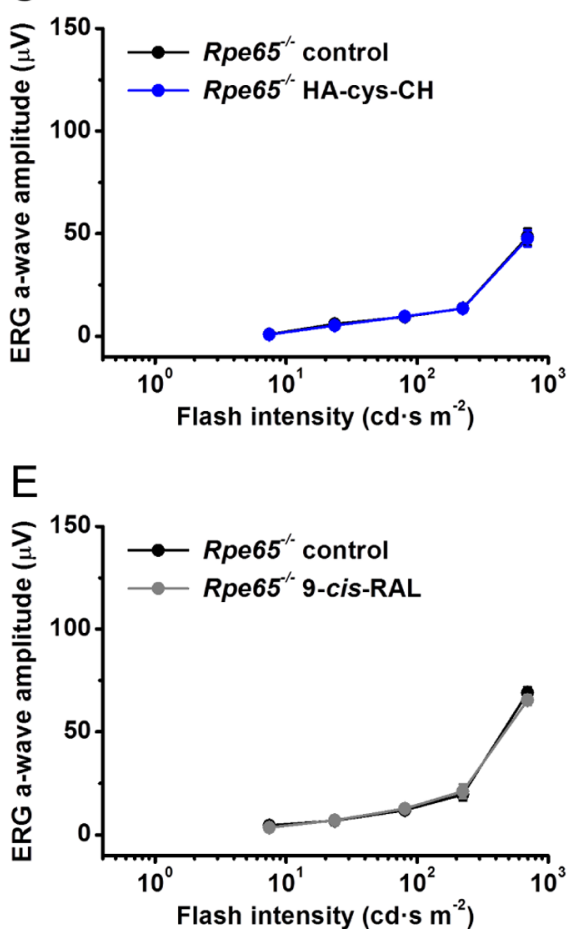

B

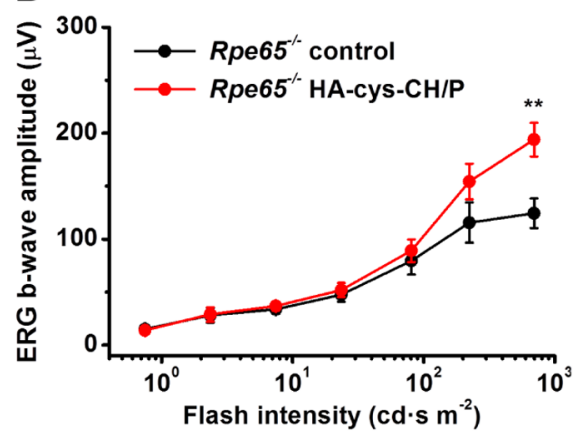

D

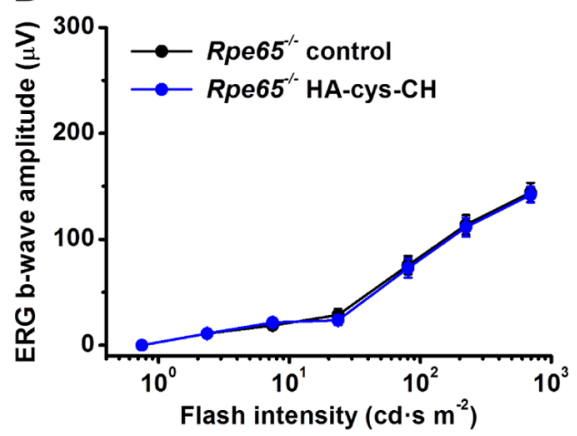

$\mathrm{F}$

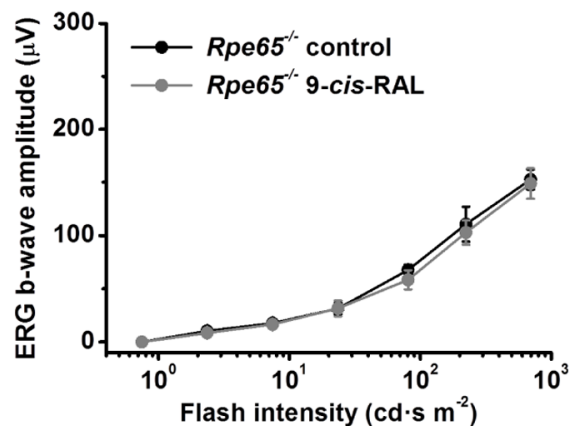

Figure 8. Topical application of nanogels loaded with 9-cis-retinal partially restores ERG a-wave and b-wave responses of chromophore-deficient mice in the presence of the penetratin peptide in vivo. (A, B) Averaged rod (scotopic) intensity-response functions (mean \pm SEM) for control untreated Rpe65 $5^{-/}$mouse left eyes $(n=8)$ and right eyes of the same animals treated with HA-cys-CH nanogels loaded with 9-cis-retinal in the presence of penetratin $(n=8)$. (C, D) Lack of response recovery in the absence of penetratin. Averaged rod intensity-response functions (mean \pm SEM) for control untreated Rpe $65^{-/-}$mouse left eyes $(n=6)$ and right eyes of the same animals treated with HA-cys-CH nanogels loaded with 9-cis-retinal in the absence of penetratin $(n=6)$. (E, F) Lack of response recovery after topical application of the visual chromophore alone. Averaged rod intensity-response functions (mean \pm SEM) for control untreated $R p e 65^{-1-}$ mouse left eyes $(n=5)$ and right eyes of the same animals treated with 9-cis-retinal only $(n=5)$. Error bars for some points in all panels are smaller than the symbol size. Statistical significance of the data is presented as $* * P<0.01$.

penetratin-assisted nanogels in vivo, the procedure is currently under further optimization to overcome several possible physical barriers imposed by the cornea of the eye and its intraocular environment. It should also be noted that the local concentration of opsins in native vertebrate photoreceptor disc membranes is exceptionally high (up to $5 \mathrm{mM}$ ). ${ }^{61}$ This dictates the need for further improving the efficiency of nanogel loading with retinoids available for release and eventual pigment regeneration. Yet, the efficient delivery of other therapeutic-loaded $\mathrm{HA}-\mathrm{cys}-\mathrm{CH} / \mathrm{P}$ nanogels, effective at smaller therapeutical dosages, to the RPE may not require such large loads.

\section{CONCLUSIONS}

The present work reports the synthesis of redox-responsive hyaluronic acid-based nanogels that are complexed with penetratin to deliver therapeutics to the posterior segment of the eye. Upon their topical application, the nanogels can reach the RPE cells and deliver their load in response to the cells' reducing environment. As a proof of concept, the visual chromophore analog, 9-cis-retinal, was loaded into the HAbased nanogels and showed robust recovery of photoreceptor function when applied to isolated retinas and a partial recovery of photoreceptor function in all treated eyes compared to untreated controls after topical application in vivo. Though the procedure requires further optimization, the drug delivery system reported here constitutes a promising alternative to 
currently used methods for administering retinoid-based compounds and, possibly, other drugs to the retina.

\section{MATERIALS AND METHODS}

4.1. Animals. Wild-type mice with a $129 \mathrm{~S} 2 / \mathrm{Sv}$ genetic background were obtained from Charles River Laboratories. Mice with a conventional knockout of the retinal pigmented epithelium protein $65 \mathrm{kDa}$ gene $\left(R p e 65^{-/-}\right)$were described previously. ${ }^{5 \frac{3}{3}}$ Young adult animals of either sex (5-6-week-old) were used. Animals were provided with standard chow (LabDiet 5053; LabDiet, Purina Mills) and maintained under a $12 \mathrm{~h}$ light/ $12 \mathrm{~h}$ dark cycle. Mice were dark-adapted overnight before physiological recordings. All experimental protocols followed the Guide for the Care and Use of Laboratory Animals and were approved by the Washington University Animal Studies Committee.

4.2. Materials. Sodium hyaluronate having a molecular weight of $10 \mathrm{kDa}$ was purchased from Lifecore (Chaska, MN). Cholesteryl chloroformate, cystamine dihydrochloride, trimethylamine, $N$-(3-dimethylaminopropyl)- $N^{\prime}$-ethylcarbodiimide hydrochloride (EDC), N-hydroxysuccinimide (NHS), anhydrous dichloromethane (DCM), and dimethyl sulfoxide (DMSO) were all obtained from Sigma-Aldrich (St. Louis, MO) and were used as received unless otherwise stated. ARPE-19 (retinal pigment epithelial) cells were purchased from American Type Culture Collection (Manassas, VA).

4.3. Synthesis of Hyaluronic Acid-Cystamine-Cholesterol Conjugate (HA-Cys-CH). The synthesis of HAcys- $\mathrm{CH}$ was conducted according to Figure 1. Initially, cystamine dihydrochloride was neutralized as follows: $4 \mathrm{~g}$ of cystamine dihydrochloride was added to $150 \mathrm{~mL}$ of methanol. After stirring for $2 \mathrm{~h}$ at room temperature (RT), $1.5 \mathrm{~g}$ of $\mathrm{NaOH}$ was added, and the mixture was stirred for $10 \mathrm{~h}$ at room temperature. The solvent was completely removed by vacuum, and $50 \mathrm{~mL}$ of anhydrous DCM was added, followed by removing the precipitate by vacuum filtration. Finally, the solvent volume was brought to $10 \mathrm{~mL}$ under vacuum, and this volume was used immediately in the next step.

In the next step, cholesteryl chloroformate ( $0.6 \mathrm{~g}, 1.34$ mmol) and $160 \mu \mathrm{L}$ of triethylamine were added to the neutralized cystamine solution. The mixture was stirred at RT for $24 \mathrm{~h}$, followed by washing with $20 \mathrm{~mL}$ of $0.2 \mathrm{M}$ aqueous (aq) $\mathrm{HCl}$ once. The aqueous phase was then washed with DCM $20 \mathrm{~mL}$ twice, and the combined organic phases were washed with brine $(20 \mathrm{~mL}$ once), dried with sodium sulfate, and filtered. Finally, dichloromethane was evaporated by a stream of nitrogen to afford the product as a pale yellow powder (yield $85 \%$ ).

Before the conjugation of cholesterol to HA, sodium hyaluronate was converted to its acidic form to dissolve in DMSO. This was done by dissolving sodium hyaluronate (200 $\mathrm{mg}$ ) in $10 \mathrm{~mL}$ of Milli-Q water and dialyzing it (molecular weight cut-off (MWCO) $3500 \mathrm{Da}$ ) against aqueous $\mathrm{HCl}(0.01$ $\mathrm{M}, 1.8 \mathrm{~L}$ ) for $20 \mathrm{~h}$, followed by another dialysis against $1.8 \mathrm{~L}$ of Milli-Q water for $20 \mathrm{~h}$. The solution was lyophilized overnight to yield a cotton-like solid. The molecular weights of sodium hyaluronate and hyaluronic acid remain the same, indicating that this conversion did not degrade the polymer (data not shown). Next, hyaluronic acid (30 mg, $0.079 \mathrm{mmol}$ ) was dissolved in $4 \mathrm{~mL}$ of anhydrous DMSO. To that were added EDC (15 mg, $0.079 \mathrm{mmol})$, NHS (7.5 mg, $0.079 \mathrm{mmol})$, and cholesterol-cystamine ( $\mathrm{CH}-$ cys, $35.8 \mathrm{mg}, 0.063 \mathrm{mmol}$ ) previously dissolved in $2 \mathrm{~mL}$ of DMSO. The mixture, which was opaque upon addition of $\mathrm{CH}-$ cys, was stirred at RT for 6 $h$, followed by purification by centrifugation to remove the precipitates. The supernatant was dialyzed against DI water, and the final product was recovered by freeze drying.

4.4. Preparing and Loading Nanogels with Fluorescein. To study the release profile of the loaded nanogels, fluorescein was selected as a model hydrophobic molecule to load, through physical entrapment, because of its low detection limit by fluorescence spectroscopy. For that, the following protocol was adopted:

First, $5 \mathrm{mg}$ of HA-cys-CH was dissolved in $1 \mathrm{~mL}$ of DMSO (with brief heating at $60{ }^{\circ} \mathrm{C}$ ). Next, $0.5 \mathrm{mg}$ of fluorescein was added in one time, followed by dropwise addition of $5 \mathrm{~mL}$ of DI water. This solution was further stirred for $1 \mathrm{~h}$ at RT and dialyzed against PBS buffer at $\mathrm{pH} 7.4$ (MWCO $3500 \mathrm{Da}, 3 \mathrm{~L} \times 2$ ) for 2 days to remove the unencapsulated free fluorescein. The loaded nanogels were then cross-linked, as previously reported. ${ }^{39,62}$ Briefly, the solution's $\mathrm{pH}$ was adjusted to $\sim 8.5$ with $1 \mathrm{~N} \mathrm{NaOH}$, followed by nitrogen bubbling for $10 \mathrm{~min}$. DTT $(163 \mu \mathrm{g}, 10 \%$ relative to the cholesterol moiety) was added, and the reaction was allowed to proceed for $22 \mathrm{~h}$. Finally, the cross-linked nanogels were dialyzed against DI water $(3 \mathrm{~L} \times 2)$ for 2 days, lyophilized, and stored at $-20{ }^{\circ} \mathrm{C}$ before further use.

4.5. Release Profile of the Loaded Nanogels. Fluorescein release was studied with and without reducing conditions. On one side, cross-linked nanogels (1 mg in $10 \mathrm{~mL}$ of release buffer) were dispersed in a solution containing 10 mmol DTT and dialyzed (MWCO $6000 \mathrm{Da}$ ) against the same solution ( $0.926 \mathrm{~g}$ of DTT in $600 \mathrm{~mL}$ of PBS). On the other side, cross-linked nanogels ( $1 \mathrm{mg}$ in $10 \mathrm{~mL}$ of release buffer) were dispersed and dialyzed against the same buffer $(600 \mathrm{~mL}$ of PBS only). At various times, $10 \mathrm{~mL}$ from the dialysate was taken out and replaced with the same release buffer volume. Fluorescence spectroscopy was used to study the release profile of fluorescein.

4.6. Carbon Dot Synthesis and Their Conjugation to HA-Cys-CH Nanogels. Carbon dots (CD) were synthesized according to our previously reported protocol. ${ }^{49}$ A stock solution of citric acid was first prepared by dissolving $28.39 \mathrm{~g}$ of citric acid in a volume of $220 \mathrm{~mL}$ of water. From this solution, $7.34 \mathrm{~mL}$ was taken and added to a $100 \mathrm{~mL}$ beaker, followed by adding DI water to make a total volume of $10 \mathrm{~mL}$, then $840 \mu \mathrm{L}$ of ethylenediamine (99\%) was added. The mixture was shaken, then transferred to a microwave oven (General Electric, $1100 \mathrm{~W}$ ), heated for $88 \mathrm{~s}$. The resulting solid was dissolved in $3 \mathrm{~mL}$ of water then transferred to a $20 \mathrm{~mL}$ vial. Another $2 \mathrm{~mL}$ of DI water was used to rinse the beaker, and the liquid portions were combined. The solution was, finally, dialyzed against water (MWCO $500 \mathrm{Da})$.

For $\mathrm{CD}$ conjugation to $\mathrm{HA}, \mathrm{HA}-\mathrm{cys}-\mathrm{CH}(10 \mathrm{mg}, 0.026$ $\mathrm{mmol}$ ) was dissolved in $4 \mathrm{~mL}$ of anhydrous DMSO with slight heating at $60{ }^{\circ} \mathrm{C}$. EDC $(5 \mathrm{mg}, 0.026 \mathrm{mmol})$, NHS $(3 \mathrm{mg}$, $0.026 \mathrm{mmol}$ ), and carbon dots (22 mg, MW $1512 \mathrm{~g} / \mathrm{mol}$, dissolved in $1 \mathrm{~mL}$ of DMSO under heating and sonication) were all added to $\mathrm{HA}-\mathrm{cys}-\mathrm{CH}$ solution, and the mixture was stirred at RT overnight. The product was purified by dialysis against DI water twice and freeze-dried overnight to recover the product as a light brown cotton-like solid.

4.7. Fluorescein-Amine Synthesis and Its Conjugation to HA-Cys-CH Nanogels. A solution of fluorescein (fluorescein isothiocyanate (FITC), $100 \mathrm{mg}, 0.257 \mathrm{mmol}$ ) in 3 $\mathrm{mL}$ of anhydrous dimethylformamide (DMF) was added 
dropwise into a solution of ethylenediamine $(15 \mathrm{mg}, 17 \mu \mathrm{L}$, $0.257 \mathrm{mmol}$ ) in $2 \mathrm{~mL}$ of anhydrous DMF. The reaction mixture was stirred for $4 \mathrm{~h}$ at $\mathrm{RT}$, followed by removing the solvent in vacuo. The reaction product was recovered as an orange solid and was used without further purification.

$\mathrm{HA}-\mathrm{cys}-\mathrm{CH}(20 \mathrm{mg})$ was dissolved in $4 \mathrm{~mL}$ of DMSO at $50{ }^{\circ} \mathrm{C}$. The solution was cooled to RT, and EDC ( $\left.3 \mathrm{mg}\right)$, NHS (5 mg), and fluorescein-amine $(10 \mathrm{mg})$ were added at once. The reaction mixture was stirred at RT overnight, followed by dialysis (MWCO $3500 \mathrm{Da}$ ) against DI water to remove unreacted reactants. The product was finally recovered by freeze drying.

4.8. Determination of Biocompatibility of the Nanogels with ECIS. The nanogels were dispersed in Dulbecco's modified Eagle's medium/Nutrient Mixture F-12 Ham (DMEM/F-12). The in vitro biocompatibility of the nanogels was analyzed in real time using electrical cell-substrate impedance sensing (ECIS) by exposing ARPE-19 cells to $\mathrm{HA}-\mathrm{cys}-\mathrm{CH}$ and $\mathrm{HA}-\mathrm{cys}-\mathrm{CH} / \mathrm{P}$ nanogels at five different concentrations $(0.25,0.5,1,2$, or $4 \mathrm{mg} / \mathrm{mL})$. Penetratin complexation to $\mathrm{HA}$ was at a weight ratio of $\mathrm{HA} /$ penetratin 2:1. The ARPE-19 cells were seeded at 20000 cells/well in an ECIS cell cultureware, a 96-well plate. The nanogel solutions were then added at the end of $24 \mathrm{~h}$ of cell initial cell seeding when a confluent layer is formed (indicated by a stable impedance signal). Eight controls per condition were used.

For the ECIS analysis, the statistical significance was evaluated using analysis of variance (ANOVA) to compare the results with the respective negative control group (untreated cells). ${ }^{*} P<0.05$, the significance level, was statistically acceptable $(n=8)$.

ECIS is a noninvasive technique that measures the impedance across gold electrodes at the bottom of each tissue culture well, using a range of frequencies of alternating current. After the initial seeding, the cells start to grow over the gold electrodes and block the current flow; as a result, the impedance across the electrodes increases. ${ }^{42,63}$ In response to stimuli, in this case, the nanogels, the degree to which cells are attached to the electrodes may change. This change is reflected in the impedance recordings in real time. The biocompatibility is interpreted as the decrease or increase in impedance compared to the negative control cells, which are not exposed to any stimuli.

4.9. In Vitro Cellular Uptake with and without Penetratin Complexation. The time-dependent cellular internalization of nanogels was monitored with ARPE-19 cells using a nanoplasmonic confocal laser-scanning microscope (Leica TCS-SP8). Two laser wavelengths were used to visualize the nucleus and the nanogels, 405 and $635 \mathrm{~nm}$, respectively, during confocal imaging.

The ARPE-19 cells were seeded in CELLview plates at $5 \times$ $10^{4}$ cells/well for $24 \mathrm{~h}$. The cells were then incubated with 2 $\mathrm{mg} / \mathrm{mL}$ nanogels modified and nonmodified with the penetratin peptide for $30 \mathrm{~min}, 1 \mathrm{~h}, 2 \mathrm{~h}$, and $4 \mathrm{~h}$. To complex them with penetratin, $\mathrm{HA}-\mathrm{cys}-\mathrm{CH}$ nanogels were then mixed with the penetratin peptide at a 2:1 weight ratio, followed by vortexing for $30 \mathrm{~s}$ to yield penetratin-complexed nanogels $(\mathrm{HA}-\mathrm{cys}-\mathrm{CH} / \mathrm{P})$. After each incubation time point with the nanogels, the cells were rinsed with PBS ( $\mathrm{pH} 7.4)$. The cells were fixed by immersion in $4 \%$ paraformaldehyde (PFA) as the cross-linking solution for $15 \mathrm{~min}$ at room temperature. The cells were washed three times with ice-cold $1 \times$ PBS for $3 \mathrm{~min}$ each time. Next, the fixed cells were incubated in ice-cold $1 \times$
PBS buffer containing $0.1 \%$ Triton X-100 (permeabilization agent) for $10 \mathrm{~min}$ at room temperature, then washed three times with ice-cold $1 \times \mathrm{PBS}$, for $5 \mathrm{~min}$ each time. The CELLview plates were then incubated with the blocking buffer for $30 \mathrm{~min}$ at room temperature. The cells were subsequently washed three times with ice-cold $1 \times$ PBS for 3 min each time. To stain the nuclei, SlowFade Gold Antifade Mountant with DAPI (diluted 1:100 in 1× PBS) was used. The cells were kept at $4{ }^{\circ} \mathrm{C}$ until confocal microscopy imaging. The cells were washed three times with ice-cold $1 \times$ PBS for 5 min each time before being transferred to the confocal microscope for visual analyses.

4.10. Loading Nanogels with 9-cis-Retinal. As a proof of concept, 9-cis-retinal, a readily available and a more stable form of the natural visual chromophore 11-cis-retinal, was loaded into $\mathrm{HA}-\mathrm{cys}-\mathrm{CH}$, as described above for fluorescein. The loading content of 9-cis-retinal inside the nanogels was determined by UV-vis spectroscopy (after determination of $\lambda_{\max }=378 \mathrm{~nm}$ of 9-cis-retinal in DMSO). A standard curve was derived from various concentrations of 9-cis-retinal in DMSO.

4.11. Ex Vivo ERG Recordings from Isolated Mouse Retinas. Mice were dark-adapted overnight, sacrificed by $\mathrm{CO}_{2}$ asphyxiation, and a whole retina was removed from each mouse eyecup under infrared illumination. The retina was mounted on a filter paper with the photoreceptor side up and placed in a perfusion chamber between two electrodes connected to a differential amplifier. The tissue was perfused with Locke's solution containing $112.5 \mathrm{mM} \mathrm{NaCl}, 3.6 \mathrm{mM}$ $\mathrm{KCl}, 2.4 \mathrm{mM} \mathrm{MgCl}_{2}, 1.2 \mathrm{mM} \mathrm{CaCl}, 10 \mathrm{mM} \mathrm{N}$-(2hydroxyethyl)piperazine- $N^{\prime}$-ethanesulfonic acid (HEPES), $\mathrm{pH} 7.4,20 \mathrm{mM} \mathrm{NaHCO} 3,3 \mathrm{mM}$ Na succinate, $0.5 \mathrm{mM} \mathrm{Na}$ glutamate, $0.02 \mathrm{mM}$ ethylenediaminetetraacetic acid (EDTA), and $10 \mathrm{mM}$ glucose. This solution was supplemented with 2 $\mathrm{mM}$ L-glutamate and $10 \mu \mathrm{M}$ DL-2-amino-4-phosphonobutyric acid (DL-AP4) to block postsynaptic components of the photoresponse ${ }^{64}$ and with $20 \mu \mathrm{M} \mathrm{BaCl}_{2}$ to suppress the slow glial PIII component. ${ }^{65}$ MEM vitamins and MEM amino acid solutions (Sigma) were also added to improve retina viability. The perfusion solution was continuously bubbled with a $95 \%$ $\mathrm{O}_{2} / 5 \% \mathrm{CO}_{2}$ mixture and heated to $36-37{ }^{\circ} \mathrm{C}$.

Light stimulation was applied in $20 \mathrm{~ms}$ test flashes of calibrated $505 \mathrm{~nm}$ light-emitting diode (LED) light. The stimulating light intensity was controlled by a computer in 0.5 $\log$ unit steps. Intensity-response relationships were fitted with Naka-Rushton hyperbolic functions, as follows

$$
R=\frac{R_{\max } \cdot I^{n}}{I^{n}+I_{1 / 2}^{n}}
$$

where $R$ is the transient-peak amplitude of the response, $R_{\max }$ is the maximal response amplitude, $I$ is the flash intensity, $n$ is the Hill coefficient (exponent), and $I_{1 / 2}$ is the half-saturating light intensity. Photoresponses were amplified by a differential amplifier (DP-311, Warner Instruments), low-pass filtered at $30 \mathrm{~Hz}$ (8-pole Bessel), digitized at $1 \mathrm{kHz}$, and stored on a computer for further analysis. Data were analyzed with Clampfit 10.4 and Origin 8.5 software. Data were expressed as means \pm SEM and analyzed using the independent twotailed Student's $t$-test, with an accepted significance level of $P<$ 0.05 .

4.12. Acute Application of 9-cis-Retinal-Loaded Nanogels to Mouse Retinas. HA-cys-CH nanogels (1.5 g, containing $\sim 300 \mu \mathrm{g}$ of 9-cis-retinal) and $0.75 \mathrm{mg}$ of the 
penetratin peptide were suspended thoroughly in $8 \mathrm{~mL}$ of $\mathrm{L} 15$ cell culture solution $(13.6 \mathrm{mg} / \mathrm{mL}, \mathrm{pH} 7.4$, Sigma) containing $1 \%$ bovine serum albumin (BSA), in the dark. The final concentration of the retinoid was estimated to be $\sim 130 \mu \mathrm{M}$. A whole mouse retina on the filter paper was incubated in a Petri dish with $2-2.5 \mathrm{~mL}$ of this oxygenated solution for $3.5-4 \mathrm{~h}$ in the dark at RT. Control retina from the second mouse eye was incubated 3.5-4 h in the same L15 solution without nanogels and retinoid. In a separate control experiment, an equivalent amount of 9-cis-retinal in L15 $(\sim 130 \mu \mathrm{M}$, dissolved in $0.1 \%$ $\mathrm{EtOH}$ ) was applied to the retina for $1 \mathrm{~h}$. The tissue was then transferred to the perfusion chamber for ex vivo ERG recordings, as described above.

4.13. Topical Application of Fluorescein-Conjugated Nanogels. With the room lights off, $20 \mu \mathrm{L}$ of the prepared penetratin-complexed nanogel solution in $1 \times$ PBS $(0.5 \mathrm{mg} /$ $\mathrm{mL}$ ) was instilled on the right eye of each live unanesthetized wild-type mouse, and an equal volume of control samples from either fluorescein solution only or PBS solution was applied to its left eye. The animal was immediately placed on the top part of a standard cage. Its tail was handled gently for $15 \mathrm{~min}$ to restrict the freedom of the animal's movement and prevent it from removing the solutions from the eyes. After visible infiltration of most of the solutions into the eyes, the mouse was allowed to move freely in its cage for another $15 \mathrm{~min}$. The animal was then sacrificed by $\mathrm{CO}_{2}$ asphyxiation, and both eyes were quickly removed and fixed for immunohistochemistry. Next, the eyes were fixed in $4 \%$ paraformaldehyde for $24 \mathrm{~h}$ and then processed routinely through graded alcohol and cleared with xylenes and infiltrated through four changes of paraffin. The eyes were embedded in a sagittal manner. The samples were cut at $4 \mu \mathrm{m}$ on a rotary microtome, and slides were dried for $30 \mathrm{~min}$ at $60{ }^{\circ} \mathrm{C}$. The slides were deparaffinized in xylenes and rehydrated through a series of graded alcohol. After rinsing well in distilled water, the slides were washed with PBS and coverslipped with VECTASHIELD HardSet Mounting Medium with DAPI. The VECTASHIELD mounting medium was from Vector Laboratories. Finally, the slides were visualized under a confocal microscope (Zeiss LSM800) to investigate nanogel's distribution in the eye.

4.14. In Vivo ERG Analysis. Dark-adapted Rpe $65^{-/-}$mice were anesthetized with an intraperitoneal injection of a mixture of ketamine $(100 \mathrm{mg} / \mathrm{kg})$ and xylazine $(20 \mathrm{mg} / \mathrm{kg})$. Pupils were dilated with a drop of $1 \%$ atropine sulfate. Mouse body temperature was maintained at $37^{\circ} \mathrm{C}$ with a heating pad. ERG responses were recorded from both eyes by corneal contact electrodes held in place by a drop of Gonak solution. Full-field ERGs were performed with the UTAS BigShot apparatus (LKC Technologies, Gaithersburg, MD) using Ganzfeldderived test flashes of calibrated green $530 \mathrm{~nm}$ LED light (within a range from 0.75 to $23.5 \mathrm{~cd} \mathrm{~s} / \mathrm{m}^{2}$ ) or white light generated by the Xenon flash tube (from 80.7 to $700 \mathrm{~cd} \mathrm{~s} / \mathrm{m}^{2}$ ). Both ERG a-waves and b-waves were measured. Data were expressed as means \pm SEM and analyzed using the independent two-tailed Student's $t$-test, with an accepted significance level of $P<0.05$.

4.15. Topical Application of 9-cis-Retinal-Loaded Nanogels. An aliquot of $1 \mathrm{mg}$ of 9-cis-retinal-loaded HAcys- $\mathrm{CH}$ nanogels was suspended in $2 \mathrm{~mL}$ of $1 \times \mathrm{PBS}$ in the dark. The suspension was sonicated briefly and shaken to disperse the nanogels. Nanogels were then mixed with the penetratin peptide at a 2:1 weight ratio, followed by vortexing for $30 \mathrm{~s}$ to complex HA with penetratin via electrostatic interactions. Nanogels $(20 \mu \mathrm{L})$ were applied topically to the right eye of each dark-adapted anesthetized Rpe $65^{-/-}$mouse placed on a heating pad of the ERG apparatus. The procedure was then repeated twice, at 20 and 50 min since the beginning of the first application $(10 \mu \mathrm{L}$ of nanogels was used at these time points), and in vivo ERG recordings were performed after an additional hour, as above. Thus, a total volume of $40 \mu \mathrm{L}$ of nanogels (or PBS) was applied to each eye. In control experiments, the equivalent amount of either 9-cis-retinalloaded HA-cys- $\mathrm{CH}$ nanogels without penetratin, or free 9cis-retinal in PBS, was applied to the mouse right eye under the same treatment regimen. During these manipulations $(\sim 2 \mathrm{~h})$, the body temperature of the mouse was maintained at $37{ }^{\circ} \mathrm{C}$ with a heating pad, and the anesthesia was repeated every $30-$ $40 \mathrm{~min}$, with $\sim 1 / 2$ of the initial dose of ketamine.

\section{ASSOCIATED CONTENT}

SI Supporting Information

The Supporting Information is available free of charge at https://pubs.acs.org/doi/10.1021/acsomega.0c05535.

Schematic diagram depicting the cross-linking and decross-linking mechanism of the redox-responsive nanogels, NMR spectra of cholesteryl chloroformate, cystamine-modified cholesterol, and hyaluronic acidcholesterol conjugate; TEM image of $\mathrm{HA}-\mathrm{cys}-\mathrm{CH}$, the diameter of $\mathrm{HA}-\mathrm{cys}-\mathrm{CH}$ before and after crosslinking; atomic force microscopy (AFM) height image and height profile of $\mathrm{HA}-\mathrm{cys}-\mathrm{CH}$ nanogels (PDF)

\section{AUTHOR INFORMATION}

\section{Corresponding Author}

Nathan Ravi - Department of Ophthalmology and Visual Sciences, Washington University School of Medicine, St. Louis, Missouri 63110, United States; Department of Veterans Affairs, St. Louis Medical Center, St. Louis, Missouri 63106, United States; Department of Energy, Environmental, and Chemical Engineering, Washington University in St. Louis, St. Louis, Missouri 63110, United States; (1) orcid.org/00000003-3923-6224; Email: ravi@wustl.edu

\section{Authors}

Amine M. Laradji - Department of Ophthalmology and Visual Sciences, Washington University School of Medicine, St. Louis, Missouri 63110, United States; Department of Veterans Affairs, St. Louis Medical Center, St. Louis, Missouri 63106, United States; 이이.org/0000-0002-0277-1621

Alexander V. Kolesnikov - Department of Ophthalmology and Visual Sciences, Washington University School of Medicine, St. Louis, Missouri 63110, United States

Bedia B. Karakoçak - Department of Ophthalmology and Visual Sciences, Washington University School of Medicine, St. Louis, Missouri 63110, United States; Department of Veterans Affairs, St. Louis Medical Center, St. Louis, Missouri 63106, United States; 이이이.org/0000-0001-9676-7465

Vladimir J. Kefalov - Department of Ophthalmology and Visual Sciences, Washington University School of Medicine, St. Louis, Missouri 63110, United States

Complete contact information is available at: https://pubs.acs.org/10.1021/acsomega.0c05535

\section{Notes}

The authors declare no competing financial interest. 


\section{ACKNOWLEDGMENTS}

The authors are grateful to the Veterans Research \& Education Foundation of St. Louis and to the VA St. Louis Health Care System for their support. This work was supported by an unrestricted grant to the Department of Ophthalmology and Visual Sciences at Washington University School of Medicine in St. Louis from Research to Prevent Blindness. This work was supported by the National Eye Institute of the National Institutes of Health under award numbers P30 EY002687, EY025696, and EY027387. This research was also funded by the VA Merit Review Grant. The authors acknowledge the financial support from Washington University in St. Louis and the Institute of Materials Science and Engineering for the use of instruments and staff assistance.

\section{REFERENCES}

(1) Nguyen, H.; Eng, S.; Ngo, T.; Dass, C. R. Delivery of therapeutics for deep-seated ocular conditions - status quo. J. Pharm. Pharmacol. 2018, 70, 994-1001.

(2) Scholl, H. P. N.; Strauss, R. W.; Singh, M. S.; Dalkara, D.; Roska, B.; Picaud, S.; Sahel, J. A. Emerging therapies for inherited retinal degeneration. Sci. Transl. Med. 2016, 8, No. 368rv6.

(3) Veleri, S.; Lazar, C. H.; Chang, B.; Sieving, P. A.; Banin, E.; Swaroop, A. Biology and therapy of inherited retinal degenerative disease: insights from mouse models. Dis. Models Mech. 2015, 8, 109129.

(4) Kiser, P. D.; Golczak, M.; Palczewski, K. Chemistry of the Retinoid (Visual) Cycle. Chem. Rev. 2014, 114, 194-232.

(5) Wang, J. S.; Kefalov, V. J. The Cone-specific visual cycle. Prog. Retinal Eye Res. 2011, 30, 115-128.

(6) Sparrrow, J. R.; Hicks, D.; Hamel, C. P. The Retinal Pigment Epithelium in Health and Disease. Curr. Mol. Med. 2010, 10, 802823.

(7) Redmond, T. M.; Yu, S.; Lee, E.; Bok, D.; Hamasaki, D.; Chen, N.; Goletz, P.; Ma, J. X.; Crouch, R. K.; Pfeifer, K. Rpe65 is necessary for production of 11-cis-vitamin A in the retinal visual cycle. Nat. Genet. 1998, 20, 344-351.

(8) Strauss, O. The retinal pigment epithelium in visual function. Physiol. Rev. 2005, 85, 845-881.

(9) Jacobson, S. G.; Cideciyan, A. V.; Ratnakaram, R.; Heon, E.; Schwartz, S. B.; Roman, A. J.; Peden, M. C.; Aleman, T. S.; Boye, S. L.; Sumaroka, A.; Conlon, T. J.; Calcedo, R.; Pang, J. J.; Erger, K. E.; Olivares, M. B.; Mullins, C. L.; Swider, M.; Kaushal, S.; Feuer, W. J.; Iannaccone, A.; Fishman, G. A.; Stone, E. M.; Byrne, B. J.; Hauswirth, W. W. Gene Therapy for Leber Congenital Amaurosis Caused by RPE65 Mutations Safety and Efficacy in 15 Children and Adults Followed Up to 3 Years. Arch. Ophthalmol. 2012, 130, 9-24.

(10) Bennett, J.; Wellman, J.; Marshall, K. A.; McCague, S.; Ashtari, M.; DiStefano-Pappas, J.; Elci, O. U.; Chung, D. C.; Sun, J. W.; Wright, J. F.; Cross, D. R.; Aravand, P.; Cyckowski, L. L.; Bennicelli, J. L.; Mingozzi, F.; Auricchio, A.; Pierce, E. A.; Ruggiero, J.; Leroy, B. P.; Simonelli, F.; High, K. A.; Maguire, A. M. Safety and durability of effect of contralateral-eye administration of AAV2 gene therapy in patients with childhood-onset blindness caused by RPE65 mutations: a follow-on phase 1 trial. Lancet 2016, 388, 661-672.

(11) Bainbridge, J. W. B.; Smith, A. J.; Barker, S. S.; Robbie, S.; Henderson, R.; Balaggan, K.; Viswanathan, A.; Holder, G. E.; Stockman, A.; Tyler, N.; Petersen-Jones, S.; Bhattacharya, S. S.; Thrasher, A. J.; Fitzke, F. W.; Carter, B. J.; Rubin, G. S.; Moore, A. T.; Ali, R. R. Effect of gene therapy on visual function in Leber's congenital amaurosis. N. Engl. J. Med. 2008, 358, 2231-2239.

(12) Duncan, J. L.; Pierce, E. A.; Laster, A. M.; Daiger, S. P.; Birch, D. G.; Ash, J. D.; Iannaccone, A.; Flannery, J. G.; Sahel, J. A.; Zack, D. J.; Zarbin, M. A.; Fdn Fighting Blindness, S. Inherited Retinal Degenerations: Current Landscape and Knowledge Gaps. Transl. Vis. Sci. Technol. 2018, 7, No. 6.
(13) Gearhart, P. M.; Gearhart, C.; Thompson, D. A.; PetersenJones, S. M. Improvement of Visual Performance With Intravitreal Administration of 9-cis-Retinal in Rpe65-Mutant Dogs. Arch. Ophthalmol. 2010, 128, 1442-1448.

(14) Tang, P. H.; Fan, J.; Goletz, P. W.; Wheless, L.; Crouch, R. K. Effective and Sustained Delivery of Hydrophobic Retinoids to Photoreceptors. Invest. Ophthalmol. Visual Sci. 2010, 51, 5958-5964.

(15) Gao, S. Q.; Kahremany, S.; Zhang, J. Y.; Jastrzebska, B.; Querubin, J.; Petersen-Jones, S. M.; Palczewski, K. Retinal-chitosan Conjugates Effectively Deliver Active Chromophores to Retinal Photoreceptor Cells in Blind Mice and Dogs. Mol. Pharmacol. 2018, 93, 438-452.

(16) Ablonczy, Z.; Crouch, R. K.; Goletz, P. W.; Redmond, T. M.; Knapp, D. R.; Ma, J. X.; Rohrer, B. 11-cis-retinal reduces constitutive opsin phosphorylation and improves quantum catch in retinoiddeficient mouse rod photoreceptors. J. Biol. Chem. 2002, 277, 4049140498.

(17) Van Hooser, J. P.; Liang, Y.; Maeda, T.; Kuksa, V.; Jang, G. F.; He, Y. G.; Rieke, F.; Fong, H. K. W.; Detwiler, P. B.; Palczewski, K. Recovery of visual functions in a mouse model of Leber congenital amaurosis. J. Biol. Chem. 2002, 277, 19173-19182.

(18) Van Hooser, J. P.; Aleman, T. S.; He, Y. G.; Cideciyan, A. V.; Kuksa, V.; Pittler, S. J.; Stone, E. M.; Jacobson, S. G.; Palczewski, K. Rapid restoration of visual pigment and function with oral retinoid in a mouse model of childhood blindness. Proc. Natl. Acad. Sci. U.S.A. 2000, 97, 8623-8628.

(19) Tang, P. H.; Fan, J.; Goletz, P. W.; Wheless, L.; Crouch, R. K. Effective and sustained delivery of hydrophobic retinoids to photoreceptors. Invest. Ophthalmol. Visual Sci. 2010, 51, 5958-5964.

(20) Falavarjani, K. G.; Nguyen, Q. D. Adverse events and complications associated with intravitreal injection of anti-VEGF agents: a review of literature. Eye 2013, 27, 787-794.

(21) Hahn, P.; Jiramongkolchai, K.; Stinnett, S.; Daluvoy, M.; Kim, $\mathrm{T}$. Rate of intraoperative complications during cataract surgery following intravitreal injections. Eye 2016, 30, 1101-1109.

(22) Chen, E.; Lin, M. Y.; Cox, J.; Brown, D. M. Endophthalmitis After Intravitreal Injection: the Importance of Viridans Streptococci. Retina 2011, 31, 1525-1533.

(23) Honda, M.; Asai, T.; Oku, N.; Araki, Y.; Tanaka, M.; Ebihara, $\mathrm{N}$. Liposomes and nanotechnology in drug development: focus on ocular targets. Int. J. Nanomed. 2013, 8, 495-504.

(24) Weng, Y. H.; Liu, J.; Jin, S. B.; Guo, W. S.; Liang, X. J.; Hua, Z. B. Nanotechnology-based strategies for treatment of ocular disease. Acta Pharm. Sin. B 2017, 7, 281-291.

(25) Ghorbani, M.; Hamishehkar, H. Redox-responsive smart nanogels for intracellular targeting of therapeutic agents: applications and recent advances. J. Drug Targeting 2019, 27, 408-422.

(26) Jaggupilli, A.; Elkord, E. Significance of CD44 and CD24 as Cancer Stem Cell Markers: An Enduring Ambiguity. Clin. Dev. Immunol. 2012, No. 708036.

(27) Liu, N. P.; Roberts, W. L.; Hale, L. P.; Levesque, M. C.; Patel, D. D.; Lu, C. L.; Jaffe, G. J. Expression of CD44 and variant isoforms in cultured human retinal pigment epithelial cells. Invest. Ophthalmol. Visual Sci. 1997, 38, 2027-2037.

(28) Too, L. K.; Gracie, G.; Hasic, E.; Iwakura, J. H.; Cherepanoff, S. Adult human retinal Muller glia display distinct peripheral and macular expression of CD117 and CD44 stem cell-associated proteins. Acta Histochem. 2017, 119, 142-149.

(29) Oh, J. K.; Lee, D. I.; Park, J. M. Biopolymer-based microgels/ nanogels for drug delivery applications. Prog. Polym. Sci. 2009, 34, $1261-1282$

(30) Zhu, Y. Q.; Wang, X. X.; Chen, J.; Zhang, J.; Meng, F. H.; Deng, C.; Cheng, R.; Feijen, J.; Zhong, Z. Y. Bioresponsive and fluorescent hyaluronic acid-iodixanol nanogels for targeted $\mathrm{X}$-ray computed tomography imaging and chemotherapy of breast tumors. J. Controlled Release 2016, 244, 229-239.

(31) Khatun, Z.; Nurunnabi, M.; Nafiujjaman, M.; Reeck, G. R.; Khan, H. A.; Cho, K. J.; Lee, Y. K. A hyaluronic acid nanogel for photo-chemo theranostics of lung cancer with simultaneous light- 
responsive controlled release of doxorubicin. Nanoscale 2015, 7 , 10680-10689.

(32) Sabir, F.; Asad, M. I.; Qindeel, M.; Afzal, I.; Dar, M. J.; Shah, K. U.; Zeb, A.; Khan, G. M.; Ahmed, N.; Din, F. U. Polymeric Nanogels as Versatile Nanoplatforms for Biomedical Applications. J. Nanomater. 2019, No. 1526186.

(33) Eslami, P.; Rossi, F.; Fedeli, S. Hybrid Nanogels: Stealth and Biocompatible Structures for Drug Delivery Applications. Pharmaceutics 2019, 11, No. 71.

(34) Stuart, M. A. C.; Huck, W. T. S.; Genzer, J.; Muller, M.; Ober, C.; Stamm, M.; Sukhorukov, G. B.; Szleifer, I.; Tsukruk, V. V.; Urban, M.; Winnik, F.; Zauscher, S.; Luzinov, I.; Minko, S. Emerging applications of stimuli-responsive polymer materials. Nat. Mater. 2010, 9, 101-113.

(35) Schafer, F. Q.; Buettner, G. R. Redox environment of the cell as viewed through the redox state of the glutathione disulfide/ glutathione couple. Free Radical Biol. Med. 2001, 30, 1191-1212.

(36) Duncan, R.; Gaspar, R. Nanomedicine(s) under the microscope. Mol. Pharmaceutics 2011, 8, 2101-2141.

(37) Jiang, S. B.; Franco, Y. L.; Zhou, Y.; Chen, J. J. Nanotechnology in retinal drug delivery. Int. J. Ophthalmol. 2018, 11, 1038-1044.

(38) Shao, X. R.; Wei, X. Q.; Song, X.; Hao, L. Y.; Cai, X. X.; Zhang, Z. R.; Peng, Q.; Lin, Y. F. Independent effect of polymeric nanoparticle zeta potential/surface charge, on their cytotoxicity and affinity to cells. Cell Proliferation 2015, 48, 465-474.

(39) Li, Y. L.; Zhu, L.; Liu, Z. Z.; Cheng, R.; Meng, F. H.; Cui, J. H.; Ji, S. J.; Zhong, Z. Y. Reversibly Stabilized Multifunctional Dextran Nanoparticles Efficiently Deliver Doxorubicin into the Nuclei of Cancer Cells. Angew. Chem., Int. Ed. 2009, 48, 9914-9918.

(40) Cheng, R.; Feng, F.; Meng, F. H.; Deng, C.; Feijen, J.; Zhong, Z. Y. Glutathione-responsive nano-vehicles as a promising platform for targeted intracellular drug and gene delivery. J. Controlled Release 2011, 152, 2-12.

(41) Ryu, J. H.; Chacko, R. T.; Jiwpanich, S.; Bickerton, S.; Babu, R. P.; Thayumanavan, S. Self-Cross-Linked Polymer Nanogels: A Versatile Nanoscopic Drug Delivery Platform. J. Am. Chem. Soc. 2010, 132, 17227-17235.

(42) Karakocak, B. B.; Liang, J.; Biswas, P.; Ravi, N. Hyaluronate coating enhances the delivery and biocompatibility of gold nanoparticles. Carbohydr. Polym. 2018, 186, 243-251.

(43) Tabas, I. Consequences of cellular cholesterol accumulation: basic concepts and physiological implications. J. Clin. Invest. 2002, 110, 905-911.

(44) Milhiet, P. E.; Giocondi, M. C.; Le Grimellec, C. Cholesterol is not crucial for the existence of microdomains in kidney brush-border membrane models. J. Biol. Chem. 2002, 277, 875-878.

(45) Nielsen, E. J. B.; Kamei, N.; Takeda-Morishita, M. Safety of the Cell-Penetrating Peptide Penetratin as an Oral Absorption Enhancer. Biol. Pharm. Bull. 2015, 38, 144-146.

(46) Khafagy, E. S.; Kamei, N.; Nielsen, E. J. B.; Nishio, R.; TakedaMorishita, M. One-month subchronic toxicity study of cellpenetrating peptides for insulin nasal delivery in rats. Eur. J. Pharm. Biopharm. 2013, 85, 736-743.

(47) Liu, C.; Tai, L. Y.; Zhang, W. J.; Wei, G.; Pan, W. S.; Lu, W. Y. Penetratin, a Potentially Powerful Absorption Enhancer for Noninvasive Intraocular Drug Delivery. Mol. Pharmaceutics 2014, 11, $1218-1227$.

(48) Tai, L. Y.; Liu, C.; Jiang, K.; Chen, X. S.; Feng, L. L.; Pan, W. S.; Wei, G.; Lu, W. Y. A novel penetratin-modified complex for noninvasive intraocular delivery of antisense oligonucleotides. Int. J. Pharm. 2017, 529, 347-356.

(49) Karakoçak, B. B.; Liang, J.; Kavadiya, S.; Berezin, M. Y.; Biswas, P.; Ravi, N. Optimizing the Synthesis of Red-Emissive NitrogenDoped Carbon Dots for Use in Bioimaging. ACS Appl. Nano Mater. 2018, 1, 3682-3692.

(50) Znoiko, S. L.; Rohrer, B.; Lu, K.; Lohr, H. R.; Crouch, R. K.; $\mathrm{Ma}, \mathrm{J}$. X. Downregulation of cone-specific gene expression and degeneration of cone photoreceptors in the Rpe65-/- mouse at early ages. Invest. Ophthalmol. Visual Sci. 2005, 46, 1473-1479.
(51) Zhang, H.; Fan, J.; Li, S.; Karan, S.; Rohrer, B.; Palczewski, K.; Frederick, J. M.; Crouch, R. K.; Baehr, W. Trafficking of membraneassociated proteins to cone photoreceptor outer segments requires the chromophore 11-cis-retinal. J. Neurosci. 2008, 28, 4008-4014.

(52) Rohrer, B.; Lohr, H. R.; Humphries, P.; Redmond, T. M.; Seeliger, M. W.; Crouch, R. K. Cone opsin mislocalization in Rpe65-/- mice: a defect that can be corrected by 11-cis retinal. Invest. Ophthalmol. Visual Sci. 2005, 46, 3876-3882.

(53) Redmond, T. M.; Yu, S.; Lee, E.; Bok, D.; Hamasaki, D.; Chen, N.; Goletz, P.; Ma, J. X.; Crouch, R. K.; Pfeifer, K. Rpe65 is necessary for production of 11-cis-vitamin $\mathrm{A}$ in the retinal visual cycle. Nat. Genet. 1998, 20, 344-351.

(54) Kolesnikov, A. V.; Tang, P. H.; Kefalov, V. J. Examining the Role of Cone-expressed RPE65 in Mouse Cone Function. Sci. Rep. 2018, 8, No. 14201.

(55) Kolesnikov, A. V.; Kefalov, V. J. Transretinal ERG recordings from mouse retina: rod and cone photoresponses. J. Visualized Exp. 2012, 61, No. e3424.

(56) Fan, J.; Woodruff, M. L.; Cilluffo, M. C.; Crouch, R. K.; Fain, G. L. Opsin activation of transduction in the rods of dark-reared Rpe65 knockout mice. J. Physiol. 2005, 568, 83-95.

(57) Hurley, J. B.; Ebrey, T. G.; Honig, B.; Ottolenghi, M. Temperature and wavelength effects on the photochemistry of rhodopsin, isorhodopsin, bacteriorhodopsin and their photoproducts. Nature 1977, 270, 540-542.

(58) Sparrrow, J. R.; Hicks, D.; Hamel, C. P. The Retinal Pigment Epithelium in Health and Disease. Curr. Mol. Med. 2011, 11, 802823.

(59) Pescina, S.; Ostacolo, C.; Gomez-Monterrey, I. M.; Sala, M.; Bertamino, A.; Sonvico, F.; Padula, C.; Santi, P.; Bianchera, A.; Nicoli, S. Cell penetrating peptides in ocular drug delivery: State of the art. J. Controlled Release 2018, 284, 84-102.

(60) Varela-Fernández, R.; Diaz-Tome, V.; Luaces-Rodriguez, A.; Conde-Penedo, A.; Garcia-Otero, X.; Luzardo-Alvarez, A.; FernandezFerreiro, A.; Otero-Espinar, F. J. Drug Delivery to the Posterior Segment of the Eye: Biopharmaceutic and Pharmacokinetic Considerations. Pharmaceutics 2020, 12, No. 269.

(61) Nickell, S.; Park, P. S. H.; Baumeister, W.; Palczewski, K. Three-dimensional architecture of murine rod outer segments determined by cryoelectron tomography. J. Cell Biol. 2007, 177, 917-925.

(62) Meng, F. H.; Hennink, W. E.; Zhong, Z. Reduction-sensitive polymers and bioconjugates for biomedical applications. Biomaterials 2009, 30, 2180-2198.

(63) Liang, J.; Karakocak, B.; Struckhoff, J.; Ravi, N. Synthesis and Characterization of Injectable Sulfonate-Containing Hydrogels. Biomacromolecules 2016, 17, 4064-4074.

(64) Sillman, A. J.; Ito, H.; Tomita, T. Studies on the mass receptor potential of the isolated frog retina. I. General properties of the response. Vision Res. 1969, 9, 1435-1442.

(65) Nymark, S.; Heikkinen, H.; Haldin, C.; Donner, K.; Koskelainen, A. Light responses and light adaptation in rat retinal rods at different temperatures. J. Physiol. 2005, 567, 923-938. 